\title{
Molecular cloning of AtRS4, a seed specific multifunctional RFO synthase/galactosylhydrolase in Arabidopsis thaliana
}

\section{OPEN ACCESS}

Edited by:

Wim Van den Ende,

KU Leuven, Belgium

Reviewed by:

Simon Stutz,

University of Stuttgart, Germany

Richard C. Sicher,

USDA-Agriculture Research Service,

USA

*Correspondence:

Raimund Tenhaken,

Division of Plant Physiology,

Department of Cell Biology, University

of Salzburg, Hellibrunnerstrasse 34,

5020 Salzburg, Austria

raimund.tenhaken@sbg.ac.at

Specialty section:

This article was submitted to

Plant Physiology,

a section of the journal

Frontiers in Plant Science

Received: 10 August 2015 Accepted: 11 September 2015

Published: 29 September 2015

Citation:

Gangl R, Behmüller R and Tenhaken $R$ (2015) Molecular cloning of AtRS4, a seed specific multifunctional RFO synthase/galactosylhydrolase in Arabidopsis thaliana.

Front. Plant Sci. 6:789. doi: 10.3389/fpls.2015.00789

\section{Roman Gangl, Robert Behmüller and Raimund Tenhaken* \\ Division of Plant Physiology, Department of Cell Biology, University of Salzburg, Salzburg, Austria}

Stachyose is among the raffinose family oligosaccharides (RFOs) one of the major water-soluble carbohydrates next to sucrose in seeds of a number of plant species. Especially in leguminous seeds, e.g. chickpea, stachyose is reported as the major component. In contrast to their ambiguous potential as essential source of carbon for germination, RFOs are indigestible for humans and can contribute to diverse abdominal disorders. In the genome of Arabidopsis thaliana, six putative raffinose synthase genes are reported, whereas little is known about these putative raffinose synthases and their biochemical characteristics or their contribution to the RFO physiology in A. thaliana. In this paper, we report on the molecular cloning, functional expression in Escherichia coli and purification of recombinant AtRS4 from $A$. thaliana and the biochemical characterisation of the putative stachyose synthase (AtSTS, At4g01970) as a raffinose and high affinity stachyose synthase ( $K_{m}$ for raffinose $\left.259.2 \pm 21.15 \mu \mathrm{M}\right)$ as well as stachyose and galactinol specific galactosylhydrolase. A T-DNA insertional mutant in the AtRS4 gene was isolated. Only semi-quantitative PCR from WT siliques showed a specific transcriptional AtRS4 PCR product. Metabolite measurements in seeds of $\triangle$ AtRS4 mutant plants revealed a total loss of stachyose in $\triangle$ AtRS4 mutant seeds. We conclude that AtRS4 is the only stachyose synthase in the genome of $A$. thaliana that AtRS4 represents a key regulation mechanism in the RFO physiology of $A$. thaliana due to its multifunctional enzyme activity and that AtRS4 is possibly the second seed specific raffinose synthase beside AtRS5, which is responsible for Raf accumulation under abiotic stress.

Keywords: galactinol, galactosylhydrolase, galactosyltransferase, myo-inositol, raffinose, raffinose family oligosaccharides, stachyose, stachyose synthase

\section{Introduction}

Seeds of higher plants are entirely dependent on their stored reserves for metabolism and growth. They contain a wide range of storage compounds, among which carbohydrates occupy a special position. Seed carbohydrates make up for the most of the carbon reserves in many seeds (Bewley and Black, 1994). $\alpha$-galactosides, including raffinose family oligosaccharides (RFOs) (Han and Baik, 2006; Lahuta et al., 2010), rank next to sucrose (Suc) among water-soluble carbohydrates (WSCs) (Frias et al., 1999). 
RFOs [Suc- $(\mathrm{Gal})_{\mathrm{n}}, 1 \leq \mathrm{n}<13$ ] are water-soluble but non-reducing and non-structural derivatives of Suc to which galactosyl units are added to the glucose (Glc) moiety of Suc through $\alpha-1,6$-bonds. Raffinose [Raf, Suc- $\left.(\mathrm{Gal})_{1}\right]$ contains one galactosyl unit, whereas stachyose [Sta, Suc- $\left.(\mathrm{Gal})_{2}\right]$ has two such galactosyl units. Raf and Sta, the most prominent members of the RFOs, get accumulated in storage organs during later stages of development (Peterbauer et al., 2001).

The first step in the RFO biosynthesis is initiated by galactinol synthase (GolS, AtGS1-10; EC 2.4.1.123; Pharr et al., 1981) which catalyzes the formation of galactinol (Gol), using UDP-galactose and myo-inositol (Ino) as substrates (Liu et al., 1995, 1998) (Figure 1, reaction 1). Biosynthesis of RFOs proceeds by stepwise transfer of galactosyl units. The second step involves raffinose synthase (RafS, AtRS5, EC 2.4.1.82) (Lehle et al., 1970; Lehle and Tanner, 1973) which transfers the galactosyl unit from Gol to the C6 position of the Glc unit in Suc, forming an $\alpha-1,6$ galactosidic linkage to yield the trisaccharide Raf (Osumi et al., 2005, 2008; Egert et al., 2013) (Figure 1, reaction 2). In a third step, stachyose synthase (StaS, AtRS4, EC 2.4.1.67) (Tanner and Kandler, 1968; Lehle and Tanner, 1973) transfers the galactosyl moiety from Gol to the C6 position of the galactose (Gal) unit in Raf to yield the tetrasaccharide Sta (Holthaus and Schmitz, 1991; Peterbauer and Richter, 1998; Hoch et al., 1999) (Figure 1, reaction 3 ).

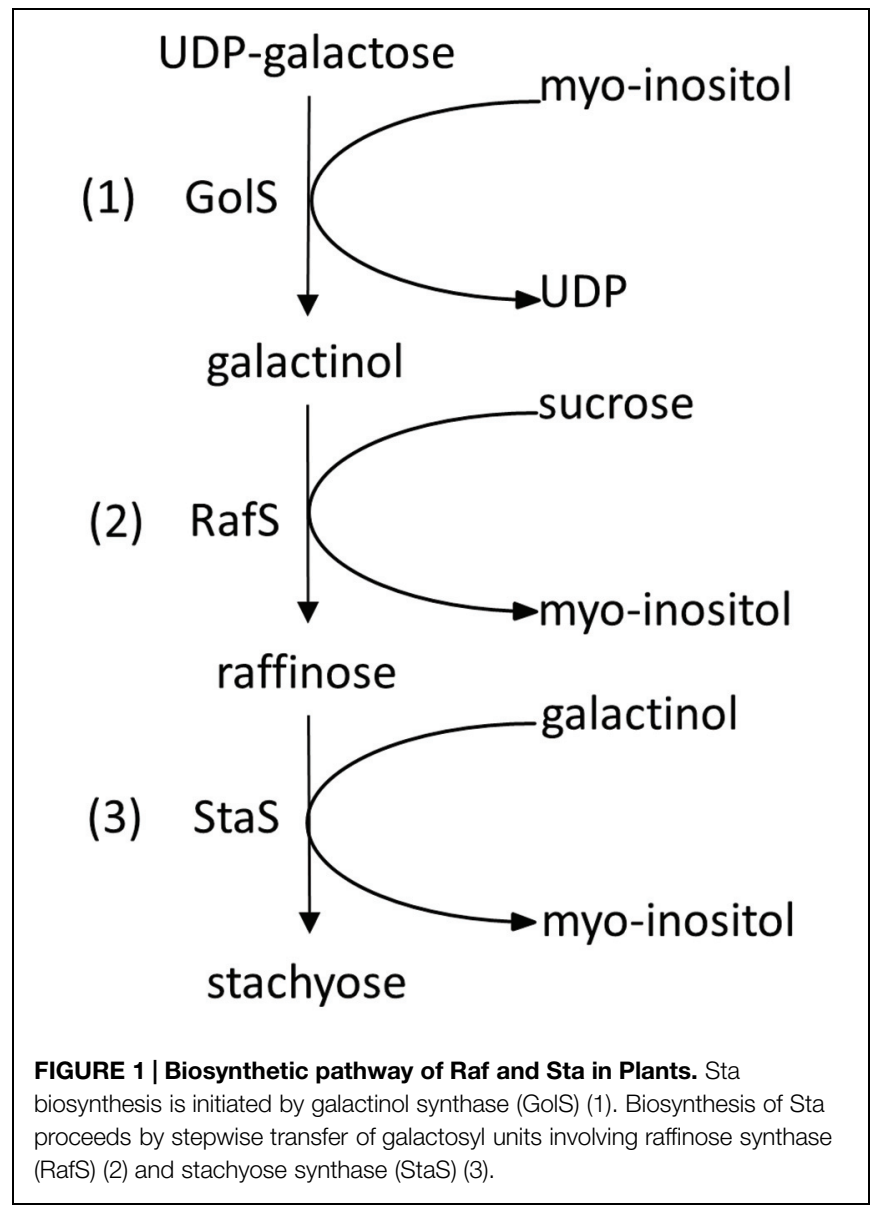

Seeds of dicotyledonous species preferentially accumulate Sta and higher homologs, like verbascose [Verb, Suc- $(\mathrm{Gal})_{3}$ ] (Kuo et al., 1988). RFOs account for more than a half of total WSCs in cowpea and soybean (Martín-Cabrejas et al., 2008). Sta is reported as the major component in chickpea and lentil flours (Sosulski et al., 1982). In Arabidopsis thaliana (A. thaliana) seeds, both Raf and Sta accumulate (Ooms et al., 1993; Bentsink et al., 2000; Nishizawa-Yokoi et al., 2008). In A. thaliana vegetative tissues, the only RFO to accumulate is Raf, occurring mainly during exposure to abiotic stress (Taji et al., 2002; Nishizawa et al., 2008).

Raf as well as Sta appears during the later stages of seed development, get accumulated in storage organs and disappear upon germination (Obendorf, 1997). After imbibition and during early stage of seed germination, RFOs get mobilized by $\alpha$-galactosidase (EC 3.2.1.22) and rapidly disappear (Zhao et al., 2006). Their breakdown is often completed before polymeric carbohydrates are mobilized (Vidal-Valverde et al., 2002; ElAdawy et al., 2003). Seeds have a high demand for energy during early germination. Since neither polymeric carbohydrates nor proteins or oils are able to meet this demand, as their breakdown is a matter of several days rather than of hours (Bewley and Black, 1994), it has been hypothesized, that RFOs as an essential source of rapidly metabolizable carbon for early germination events (Downie and Bewley, 2000) play a special role during early seed germination and that they are required for successful germination (Blöchl et al., 2007), but contradictory results scrutinize the exact role of RFOs during germination and seed development (Dierking and Bilyeu, 2009).

In contrast to their potential for promoting seed germination (Elsayed et al., 2013), RFOs particularly in leguminous seeds are indigestible due to lack of $\alpha$-galactosidase in the digestive tract and therefore anti-nutritional oligosaccharides for monogastric animals as well as for humans when consumed. Because of their indigestible $\alpha$-galactosidic linkages, RFOs end up in the large intestine, where they are fermented by the intestinal microflora and promote the growth of resident indigenous lactic acid bacteria (Liu et al., 2014). The microbial RFO breakdown produces a great deal of deleterious gasses (Cristofaro et al., 1974; Swennen et al., 2006; Kumar et al., 2010). Although there is some debate about the potential health benefits of non-digestible oligosaccharides (Delzenne and Roberfroid, 1994; Roberfroid, 2002), various physico-mechanical treatments and breeding programs have been reported to reduce RFO concentrations in seeds (Aguilera et al., 2009; Devindra et al., 2011). Even the enzymatic removal of RFOs from seed-derived products (Kulkarni et al., 2006; Patil et al., 2009) using immobilized $\alpha$-galactosidase from Aspergillus oryzae, has been extensively studied (Slominski et al., 1994; Khalil and Mansour, 1998; Feng et al., 2008; Liu et al., 2014). To improve nutritional quality of leguminous seeds, RFO concentrations need to be reduced (Qiu et al., 2015) without affecting their role during seed development. Therefore, the key regulating steps of RFO biosynthesis need to be identified.

Stachyose synthase is an important enzyme involved in the biosynthesis of RFOs, which occur frequently in higher plants, and has been identified and partially characterized from 
several sources. Generally, plant StaSs are poorly biochemically characterized, because of difficulties in expression and especially purification of functional recombinant protein. Until now, the only biochemical characterisation of StaS either as purified enzyme or from crude extracts of transformed insect cell lysate has been reported from Lentil seed (Hoch et al., 1999) and Adzuki bean (Peterbauer and Richter, 1998; Peterbauer et al., 1999). StaSs have attracted little attention, probably owing to the missed promising results on cold resistance (Iftime et al., 2011).

In this paper, we report on the molecular cloning, functional expression and purification of AtRS4 cDNA from A. thaliana in Escherichia coli and the biochemical characterization of the putative StaS (AtSTS, At4g01970) with RafS and high affinity StaS as well as Sta and Gol specific galactosylhydrolase enzyme activity of the recombinant AtRS4. Furthermore, metabolite measurements in seeds of $\triangle A t R S 4$ mutant plants revealed a total loss of Sta in $\triangle A t R S 4$ mutant seeds.

\section{Materials and Methods}

\section{Plant Material and Growth Conditions}

Arabidopsis thaliana, ecotype Columbia (wild type, WT) and $\triangle A t R S 4$ mutant seeds, were cold-treated to synchronize germination and either grown in standard fertilized soil (type ED73) or on $0.5 \times$ MS agar plates [solid Murashige Skoog phytagel medium: $0.5 \times$ MS-salts (Duchefa, BH Haarlem, Netherlands), $0.3 \%(\mathrm{w} / \mathrm{v})$ phytagel, $0.3 \%(\mathrm{w} / \mathrm{v}) \mathrm{Suc}, \mathrm{KOH}(\mathrm{pH}$ 5.7)] or on $0.5 \%$ plant agar plates (Duchefa) in a short-day growth chamber under control growth conditions at $23^{\circ} \mathrm{C}$ with $8 \mathrm{~h}$ light with approximately $100 \mu \mathrm{E} \mathrm{m}^{-2} \mathrm{~s}^{-1}$ and $16 \mathrm{~h}$ dark period. During the dark phase, temperature was decreased to $18^{\circ} \mathrm{C}$. Humidity was set to $60 \%$ during cultivation. After sampling leaf material, plants were transferred to a long-day growth chamber with $10 \mathrm{~h}$ light and $14 \mathrm{~h}$ dark period and conditions as described above. Before planting seeds on plates, seeds were surface sterilized. Samples were taken from seeds, siliques, and leaves of A. thaliana WT and $\triangle A t R S 4$ mutant plants. Germination was defined as the time between sowing and protrusion of the radicle. Three biological replicates were grown from each line and one sample was picked from each biological replicate. One seed sample consisted of $20 \mathrm{mg}$ seeds, one silique sample consisted of 30 siliques and one leaf sample consisted of two mediumsized leaves of plants that were put into pre-weighted reaction tubes together with one $3 \mathrm{~mm}$ stainless steel ball. After harvesting the plant material, sample tubes were weighted and immediately stored in liquid nitrogen. The plant material was pulverized in liquid nitrogen-cooled Teflon carriers for $2 \mathrm{~min}$ and $30 \mathrm{~Hz}$ using a ball mill (Model PM200, Retsch, Düsseldorf, Germany).

\section{DAtRS4 Mutant Plant Analysis}

The $\triangle$ AtRS4 mutant plant in the Col-0 background was obtained from the SALK collection [At4g01970, (SALK_045237)] (Alonso et al., 2003). The $\triangle A t R S 4$ mutant plant carries a T-DNA insert in the first exon of At4g01970. Genomic DNA (gDNA) was extracted from young leaves and the genetic identity of the plants determined by PCR technique. gDNA from A. thaliana leaves was extracted by the standard cetyl trimethylammonium bromide (CTAB) buffer method. Homozygous $\triangle A t R S 4$ mutant plants were identified by PCR using two different primer pairs: AtRS4 WT allele was amplified with the wtAtRS4_fwd and wtAtRS4_rev primer and $\triangle A t R S 4$ mutant allele was amplified with the SALK left border and the wtAtRS4_rev primer (Supplementary Table S1).

\section{Extraction of WSCs and Sugar Alcohols}

Liquid-liquid extraction according to Lunn et al. (2006) was applied to extract WSCs and sugar alcohols from plant material. $250 \mu \mathrm{l}$ of quenching solution (chloroform to methanol in a $3: 7(\mathrm{v} / \mathrm{v})$ ratio) were added to the pulverized samples. The samples were incubated at $-20^{\circ} \mathrm{C}$ for $2 \mathrm{~h}$ and vigorously mixed every $30 \mathrm{~min}$. WSCs and sugar alcohols were twice extracted by adding $400 \mu \mathrm{l}$ of water to the organic layer and the aqueous layer was collected after centrifugation at $13,000 \times g$ for $10 \mathrm{~min}$. The aqueous phases containing WSCs and sugar alcohols were vaporized using a vacuum concentrator (Model 5301 Concentrator plus, Eppendorf, Vienna, Austria) at $45^{\circ} \mathrm{C}$ using the AL setting (setting 3), which is recommended for alcoholic solutions. After vaporization, all samples of each biological replicate were reconstituted in $500 \mu \mathrm{l}$ water and diluted in a 1:5 (v/v) ratio with water (Behmüller et al., 2014; Gangl et al., 2014).

Recoveries of extraction of WSCs and sugar alcohols were determined individually for each WSC and sugar alcohol by extracting an aliquot of the respective WSC or sugar alcohol solution $\left(10 \mu \mathrm{mol} \mathrm{l}^{-1}\right)$ as described above and comparing the peak area obtained from triplicate high-performance anionexchange chromatography with pulsed amperometric detection (HPAEC-PAD) measurements of the extracted solution with that of a standard solution having the same concentration (Supplementary Figure S1). Linearity of WSCs and sugar alcohols in the concentration range from 5 to $100 \mu \mathrm{mol} \mathrm{l}^{-1}$ was tested with HPAEC-PAD measurements (Supplementary Figure S2).

\section{cDNA Cloning of AtRS4}

Total RNA was extracted from leaves of A. thaliana. Leaves were frozen in liquid nitrogen, homogenized with a ball mill, and extracted by TriReagent buffer method according to Chomczynski (1993). Residual DNA was removed by treatment with RNase-free DNase (Fermentas, St Leon-Rot, Germany). Single strand cDNA was synthesized from $1 \mu \mathrm{g}$ of total leaf RNA using the RevertAid First Strand cDNA synthesis kit (Fermentas, Vienna, Austria). For cloning the AtRS4 gene based on the cDNA sequence of $A$. thaliana two primers with restriction sites were designed, AtRS4_fwd with Sac and AtRS4_rev with Sma I restriction site (Supplementary Table S1). PCR was performed with Phusion High-Fidelity DNA polymerase (Thermo Scientific, Vienna, Austria) using AtRS4_fwd and AtRS4_rev primer and single-stranded cDNA as template under following conditions: initial denaturation at $98^{\circ} \mathrm{C}$ for $30 \mathrm{~s}$, followed by $5 \times\left(98^{\circ} \mathrm{C}\right.$ for $10 \mathrm{~s}, 51^{\circ} \mathrm{C}$ for $30 \mathrm{~s}, 72^{\circ} \mathrm{C}$ for $\left.90 \mathrm{~s}\right), 21 \times\left(98^{\circ} \mathrm{C}\right.$ for $10 \mathrm{~s}$, $51+1^{\circ} \mathrm{C}$ for $30 \mathrm{~s}, 72^{\circ} \mathrm{C}$ for $\left.90 \mathrm{~s}\right), 9 \times\left(98^{\circ} \mathrm{C}\right.$ for $10 \mathrm{~s}, 72^{\circ} \mathrm{C}$ for $30 \mathrm{~s}, 72^{\circ} \mathrm{C}$ for $90 \mathrm{~s}$ ) and final elongation at $72^{\circ} \mathrm{C}$ for $10 \mathrm{~min}$. The PCR product was restricted with Sac I and Sma I (Fast 
Digest; Thermo Scientific, Vienna, Austria), gel purified using GeneJet Gel Extraction Kit (Thermo Scientific, Vienna, Austria) and ligated into E. coli expression vector pQE30 (Qiagen, Hilden, Germany) using Rapid DNA Ligation Kit (Thermo Scientific, Vienna, Austria).

\section{Expression and Purification of Recombinant AtRS4}

For expression of recombinant AtRS4 from A. thaliana in E. coli cells, the expression construct was cultivated in a 11 Erlenmeyer flask containing $250 \mathrm{ml}$ of liquid LB medium supplemented with $100 \mu \mathrm{g} \mathrm{ml}^{-1}$ of ampicillin at $37^{\circ} \mathrm{C}$ to an $\mathrm{OD}_{600}$ between 0.6 and 1.0 under vigorous shaking. The culture was cooled to $18^{\circ} \mathrm{C}$ and expression of recombinant AtRS4 was induced by addition of $1 \mathrm{mM}$ Isopropyl- $\beta$-D-thiogalactopyranoside (IPTG). After $20 \mathrm{~h}$ vigorous shaking at $18^{\circ} \mathrm{C}$, cells were cooled to $4^{\circ} \mathrm{C}$ for $30 \mathrm{~min}$ before harvesting. All following purification steps were carried out at $4^{\circ} \mathrm{C}$.

The culture was split into three parts of $80 \mathrm{ml}$ each, centrifuged and pellet was stored on $-80^{\circ} \mathrm{C}$. For purification of recombinant AtRS4, the pellet was thawed and resuspended in $2 \mathrm{ml}$ of equilibration buffer $\left(50 \mathrm{mM} \mathrm{NaH} \mathrm{PO}_{4}, 300 \mathrm{mM} \mathrm{NaCl}, 1 \mathrm{mM}\right.$ DTT and a $\mathrm{pH}$ of 8.0 adjusted with $\mathrm{NaOH}$ ). Lysozyme from chicken egg was added to a final concentration of $1 \mathrm{mg} \mathrm{ml}^{-1}$ (Roche Applied Science) and the solution was gently shaken for $30 \mathrm{~min}$ on ice. After incubation, the suspension was sonicated 10 times with $60 \%$ amplitude for $10 \mathrm{~s}$ with $10 \mathrm{~s}$ cooling between each burst on ice (Sonoplus, Bandelin, Berlin, Germany). The remaining insoluble residues were removed by centrifugation for $10 \mathrm{~min}$ at $13,000 \mathrm{~g}$.

For purification of His-tagged recombinant AtRS4, the clarified supernatant was applied to pre-packed Protino ${ }^{\circledR} \mathrm{Ni}$ TED 1000 columns (Macherey and Nagel, Düren, Germany) equilibrated with $2 \mathrm{ml}$ equilibration buffer. The column was washed three times with $2 \mathrm{ml}$ of equilibration buffer and bound recombinant protein was eluted with $1.5 \mathrm{ml}$ of elution buffer $\left(50 \mathrm{mM} \mathrm{NaH}{ }_{2} \mathrm{PO}_{4}, 300 \mathrm{mM} \mathrm{NaCl}, 1 \mathrm{mM}\right.$ DTT, and $250 \mathrm{mM}$ imidazole and a $\mathrm{pH}$ of 8.0). Purified recombinant AtRS4 was analyzed by SDS-PAGE, respectively, by Western Blot, and immediately analyzed in HPAEC-PAD enzyme assays.

\section{Protein Determination}

Protein concentration was determined on the NanoDrop ${ }^{\circledast}$ ND1000 Spectrophotometer (peqLab, VWR International GmbH, Erlangen, Germany) using the method of Bradford assay with bovine serum albumin as reference protein. Since, purification of recombinant AtRS4 showed additional bands on SDS-PAGE, we performed a quantification of recombinant AtRS4, using the Gel Quantification Analysis tool of ImageJ software (Schneider et al., 2012). The eluate consists of approximately $50 \%$ of recombinant AtRS4, which was used for enzyme assay calculations.

\section{SDS-PAGE and Western Blot Analysis}

Different fractions, obtained during purification of recombinant AtRS4, were separated and analyzed for purity by SDS-PAGE using a $10 \%$ acrylamide separation gel and colloidal Coomassie blue staining. For Western blots, unstained gels were blotted onto a nitrocellulose membrane (Schleicher and Schuell Protran ${ }^{\mathrm{TM}}$ BA85) for $1 \mathrm{~h}$ at $100 \mathrm{~V}$. Non-specific binding sites were blocked by incubating the membrane for $1 \mathrm{~h}$ with TBST-BSA $(1 \% \mathrm{w} / \mathrm{v})$ at room temperature followed by two washing steps with TBST each for $15 \mathrm{~min}$. For detection of His-tagged protein, a SuperSignal West HisProbe kit (Thermo Scientific, Vienna, Austria) was used. Luminescence detection was performed using an LAS 3000 mini imaging system (Fujifilm, Dusseldorf, Germany).

\section{StaS Enzyme Activity Assay}

Detection of StaS enzyme activity was performed using HPAECPAD enzyme assays. StaS enzyme assays were carried out in $0.2 \mathrm{ml}$ reaction tubes at a final volume of $100 \mu \mathrm{l}$ containing $25 \mathrm{mM}$ $\mathrm{KH}_{2} \mathrm{PO}_{4}$ (pH 7), $400 \mu \mathrm{M}$ Raf, $100 \mu \mathrm{M}$ Gol, and $335 \mathrm{ng}$ of recombinant AtRS4. StaS enzyme assays were incubated in a PCR cycler (PCR cycler Primus 25 advanced, Peqlab, Polling, Austria) at $25^{\circ} \mathrm{C}$ for $60 \mathrm{~min}$ and reactions were stopped by heating the tubes to $95^{\circ} \mathrm{C}$ for $5 \mathrm{~min}$. For StaS enzyme activity analysis, $10 \mu \mathrm{l}$ of StaS enzyme assays were injected on the HPAEC-PAD system. In StaS enzyme assay, recombinant AtRS4 was assumed to catalyze the reaction Raf $+\mathrm{Gol} \rightarrow \mathrm{Sta}+\mathrm{Ino}$ (Figure 1, reaction 3). Determination of StaS enzyme activity and biochemical data like StaS enzyme assay linearity, buffer system optimum, $\mathrm{pH}$ optimum, temperature optimum, and enzyme kinetics of the recombinant AtRS4 were performed by measurements of Sta product formation.

\section{RafS and StaS Enzyme Activity Assay}

Detection of RafS and StaS enzyme activity was performed using HPAEC-PAD enzyme assays. RafS and StaS enzyme assays were carried out in $0.2 \mathrm{ml}$ reaction tubes at a final volume of $100 \mu \mathrm{l}$ containing $25 \mathrm{mM} \mathrm{KH} \mathrm{PO}_{4}(\mathrm{pH}$ 7), $335 \mathrm{ng}$ of recombinant AtRS4, and either $1 \mathrm{mM} \mathrm{Gol}$ and Suc in a range from $50 \mu \mathrm{M}$ to $100 \mathrm{mM}$, or $1 \mathrm{mM}$ Suc and Gol in a range from $50 \mu \mathrm{M}$ to $100 \mathrm{mM}$. RafS and StaS enzyme assays were incubated in a PCR cycler at $25^{\circ} \mathrm{C}$ for $6 \mathrm{~h}$ and reactions were stopped by heating the tubes to $95^{\circ} \mathrm{C}$ for $5 \mathrm{~min}$. For RafS and StaS enzyme activity analysis, $10 \mu \mathrm{l}$ of RafS and StaS enzyme assays were injected on HPAEC-PAD system. In RafS and StaS enzyme assay, recombinant AtRS4 was assumed to catalyze the reaction $\mathrm{Suc}+\mathrm{Gol} \rightarrow \mathrm{Raf}+\mathrm{Ino}$ (Figure 1, reaction 2) and subsequently the reaction Raf $+\mathrm{Gol} \rightarrow \mathrm{Sta}+$ Ino (Figure 1, reaction 3). Determination of RafS and StaS enzyme activity and Raf to Sta product formation ratio of the recombinant AtRS4 were performed by measurements of Raf and Sta product formation.

\section{Gol, Raf and Sta Galactosylhydrolase Enzyme Activity Assay}

Detection of galactosylhydrolase enzyme activity was performed using HPAEC-PAD enzyme assays. Galactosylhydrolase enzyme assays were carried out in $0.2 \mathrm{ml}$ reaction tubes at a final volume of $100 \mu \mathrm{l}$ containing $25 \mathrm{mM} \mathrm{KH}_{2} \mathrm{PO}_{4}$ (pH 7), $335 \mathrm{ng}$ of recombinant AtRS4 and $1 \mathrm{mM}$ of different substrates (either Gol, Raf, or Sta). Galactosylhydrolase enzyme assays were incubated in a PCR cycler at $25^{\circ} \mathrm{C}$ for $60 \mathrm{~min}$ and reactions were stopped by heating the tubes to $95^{\circ} \mathrm{C}$ for $5 \mathrm{~min}$. For galactosylhydrolase enzyme analysis, $10 \mu \mathrm{l}$ of galactosylhydrolase enzyme assays 
were injected on HPAEC-PAD system. In galactosylhydrolase enzyme assay, recombinant AtRS4 was assumed to catalyze the reaction $\mathrm{Gol} \rightarrow \mathrm{Gal}+\mathrm{Ino}$, reaction $\mathrm{Raf} \rightarrow \mathrm{Suc}+\mathrm{Gal}$, and reaction $\mathrm{Sta} \rightarrow \mathrm{Raf}+\mathrm{Gal}$. Determination of galactosylhydrolase activity and of enzyme kinetics of the recombinant AtRS4 were performed by measurements of Gal product formation.

\section{High-Performance Anion-Exchange Chromatography with Pulsed Amperometric Detection (HPAEC-PAD) of WSCs}

High-performance anion-exchange chromatography separation of WSCs produced during HPAEC-PAD enzyme assays as well as WSCs extracted from plant material was performed on a HPAEC (model ICS300, Dionex Corporation, Sunnyvale, CA, USA) consisting of an ICS3000 single pump, ICS3000 electrochemical detector and a Dionex AS autosampler (Dionex Corporation, Sunnyvale, CA, USA). For chromatography of WSCs, data were analyzed with Chromeleon 7.12 (Thermo Scientific, Vienna, Austria).

For baseline separation of Gal, Suc, Raf, Sta, and Verb as well as separation of Ino and Gol a Dionex Carbopac PA20 column (150 $\mathrm{mm} \times 3 \mathrm{~mm}$ i.d., $6.5 \mu \mathrm{m}$ particle size) with a PA20 guard column (30 mm $\times 3 \mathrm{~mm}$ i.d., $6.5 \mu \mathrm{m}$ particle size) was in use. Ino and Gol were separated on a Dionex Carbopac MA1 column (250 $\mathrm{mm} \times 4 \mathrm{~mm}$ i.d., $7.5 \mu \mathrm{m}$ particle size) with a MA1 guard column $(50 \mathrm{~mm} \times 4 \mathrm{~mm}$ i.d., $7.5 \mu \mathrm{m}$ particle size). During measurements the column oven was set to $30^{\circ} \mathrm{C}$. The mobile phase consisted of solvent A, $200 \mathrm{mM} \mathrm{NaOH}$, and solvent $\mathrm{B}$, $15 \mathrm{mM} \mathrm{NaOH}$.

Sample measurements for the analysis of WSCs extracted from plant material, especially Raf and Sta, were performed using a Dionex Carbopac PA20 column with a gradient program that employed the starting conditions of 5\% A and 95\% B at a flow rate of $0.450 \mathrm{ml} \mathrm{min}^{-1}$. Starting conditions were held for $5 \mathrm{~min}$. Subsequently, a linear gradient was programmed within $15 \mathrm{~min}$ to $25 \% \mathrm{~A}$ and $75 \% \mathrm{~B}$. These conditions were held for $5 \mathrm{~min}$. From 25 to $25.1 \mathrm{~min}$, starting conditions of $5 \% \mathrm{~A}$ and $95 \% \mathrm{~B}$ were restored and kept for $9.9 \mathrm{~min}$ (35 min total run time). Sample measurements for the analysis of WSCs produced during HPAEC-PAD enzyme assays were performed using a Dionex Carbopac PA 20 column with a shortened gradient program (18 min total run time) (Supplementary Figure S3). Sample measurements for the analysis of WSCs extracted from plant material, especially Ino and Gol, were performed using a Dionex Carbopac MA1 column with a gradient program that employed the starting conditions of $5 \% \mathrm{~A}$ and $95 \% \mathrm{~B}$ at a flow rate of $0.400 \mathrm{ml} \mathrm{min}^{-1}$, these conditions were held for $2 \mathrm{~min}$. After $2 \mathrm{~min}$ a linear gradient was established within $13 \mathrm{~min}$ to $5 \% \mathrm{~A}$ and $95 \% \mathrm{~B}$. These conditions were held for $10 \mathrm{~min}$. From 25 to $25.1 \mathrm{~min}$, starting conditions of $5 \% \mathrm{~A}$ and $95 \% \mathrm{~B}$ were restored and kept for $9.9 \mathrm{~min}$ (35 min total run time) (Supplementary Figure S4).

\section{Semi-Quantitative PCR (sqPCR)}

Semi-quantitative PCR was carried out in $30 \mu \mathrm{l}$ containing $15 \mu l 2 x$ PCR buffer [40 mM Tris/Cl ( $\mathrm{pH} 8.4), 100 \mathrm{mM} \mathrm{KCl}$, $6 \mathrm{mM} \mathrm{MgCl}_{2}, 8 \%$ glycerol, $1 \%$ BSA-Solution (10 $\mathrm{mg} \mathrm{ml}^{-1}$ ),
$320 \mu \mathrm{M}$ dNTP], $2 \mu \mathrm{l}$ 1:20 diluted cDNA, $0.3 \mu \mathrm{l} 100 \mu \mathrm{M}$ primer fwd, $0.3 \mu \mathrm{l} 100 \mu \mathrm{M}$ primer rev, $0.2 \mu \mathrm{l} 1 \mathrm{U}$ recombinant Taq polymerase, at a primer annealing temperature of $55^{\circ} \mathrm{C}$ for 35 cycles. qAtRS4_fwd and qAtRS4_rev primer (Supplementary Table S1) were designed using QuantPrime (Arvidsson et al., 2008). Target sequence was used to amplify a fragment of the corresponding cDNA.

\section{Results}

\section{Sequence Analysis}

A database search using AtRS4 sequence from A. thaliana clearly revealed homologous sequences in Vigna angularis, Cucumis melo, Pisum sativum and Alonsoa meridionalis, which are all coding for StaSs, as well as homologous sequences in P. sativum, C. sativus, Glycine max, and Oryza sativa subsp japonica, which are all coding for RafSs (Figure 2B). Both AtRS4 (Figure 2C) as well as AtRS5 (Figure 2A) amino acid sequence contain a typical motif of AmyAc_family superfamily ( $\alpha$-amylase catalytic domain) for $\alpha$-amylase family, the largest family of glycosidehydrolases. These enzymes catalyze the transformation of $\alpha$-1,4- and $\alpha$-1,6-glucosidic linkages. Furthermore, the AtRS5 (Figure 2A) amino acid sequence displays a typical motif of Raffinose_syn (RafS), whereas AtRS4 only displays a 400 amino acid long C-terminal typical motif sequence (Figure 2C), which represents several RafSs (InterPro: IPR017853), also known as seed imbibition proteins (SIP), from the glycoside hydrolase family $36^{\circ} \mathrm{C}$ (InterPro: IPR008811).

It is surprising, that only a 400 amino acid long C-terminal sequence of AtRS4 is annotated as RafS, since AtRS4 and AtRS5 amino acid sequence show 36\% identity and 54\% similarity through the whole amino acid sequence (Table 1). This misleading annotation is possibly based on homology differences of the $\mathrm{N}$ - and $\mathrm{C}$ - terminal sequences (Table 1). Despite these highly conserved amino acid sequences, one sequence block of about 80 amino acids length occur exclusively in StaS sequences (PLN02982, Gol-Raf galactosyltransferase/galactosylhydrolase) and is totally missing in RafS sequences (PLN02711, GolSuc galactosyltransferase) (Figure 2B). Thus the insertion is characteristic for StaS and allows differentiation from RafS.

\section{Cloning and Expression of AtRS4}

To confirm the biochemical function of AtRS4, which is annotated as putative StaS with either StaS and/or RafS and/or galactosylhydrolase enzyme activity, we cloned the full-length open reading frame of AtRS4 cDNA, encoding 876 amino acids with a calculated molecular mass of about $98.01 \mathrm{kDa}$, into the E. coli expression vector $\mathrm{pQE30}$ with a His-tag for production of recombinant AtRS4. We obtained soluble and functional protein. SDS-PAGE of the purified soluble recombinant protein is shown in Figure 3. The recombinant protein was detected with a His-tag specific probe, which recognized a single band of about $100 \mathrm{kDa}$ in Western blots. Expression of recombinant AtRS4 in E. coli culture produced $22 \mathrm{mg}$ of the recombinant protein per liter of cell culture with a specific StaS enzyme activity $V \max$ (Raf) of 4722 pkat $\mathrm{mg}^{-1}$ protein. 


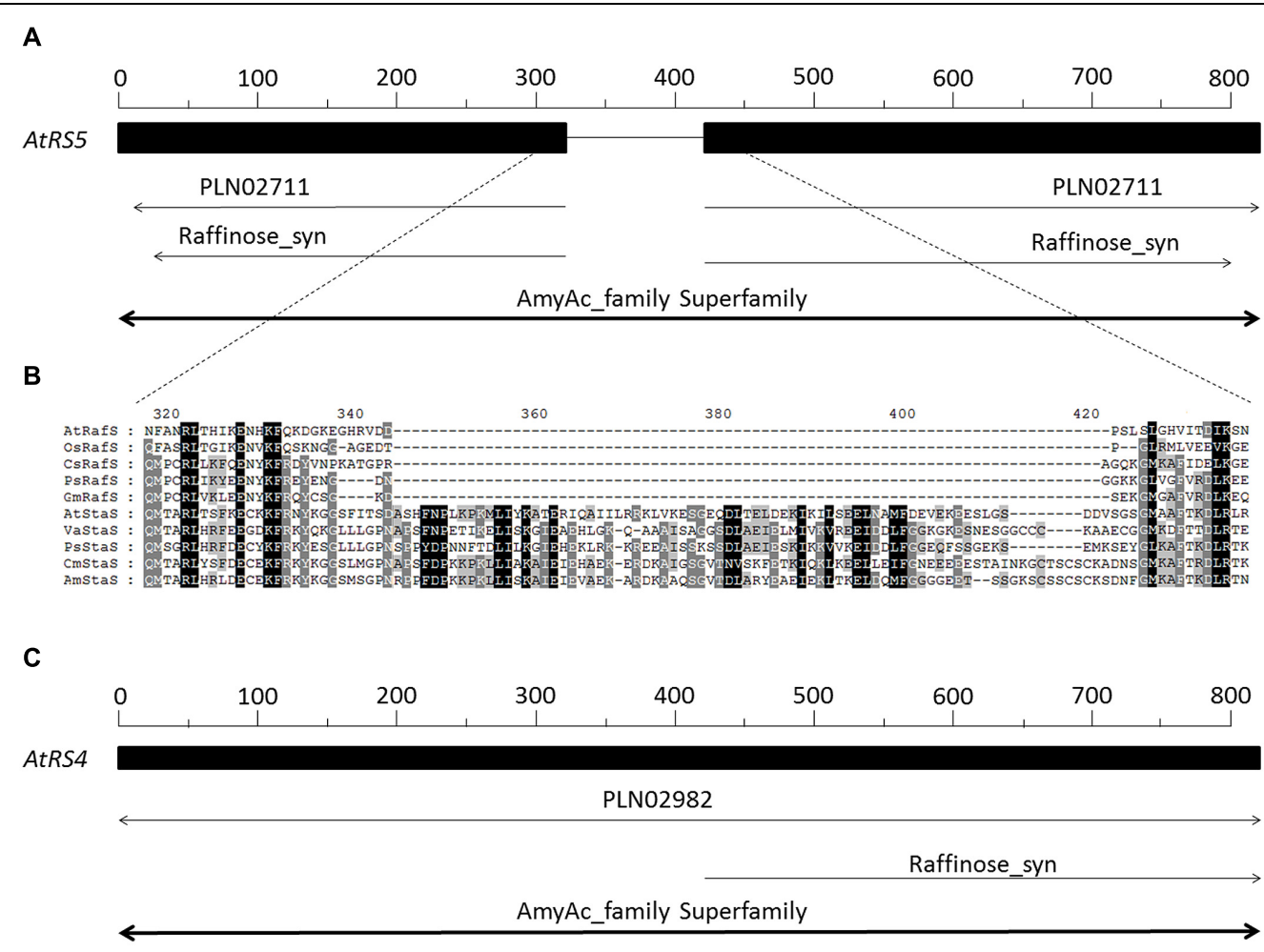

FIGURE 2 | Sequence and phylogenetic analysis of AtRS4 and AtRS5. (A) Schematically shows the 783 amino acid long sequence of AtRS5 (A5g40390) from Arabidopsis thaliana. (B) Shows a section of a sequence alignment performed with Clustal Omega (Sievers et al., 2011) of RafS and StaS amino acid sequences, which revealed very high amino acid identity and similarity, except for a 80 amino acid long sequence block insertion, which is only present in the StaS. (C) Schematically shows the 876 amino acid long sequence of AtRS4 (At4g01970) from A. thaliana. RafS amino acid sequence from A. thaliana (AtRafS, gi|332195171), Oryza sativa subsp japonica (OsRafS, gi|115471135), Cucumis sativus (CsRafS, gi|124057819), Pisum sativum (PsRafS, gil18181865) and Glycine max (GmRafS, gi|187610414). StaS amino acid sequence from A. thaliana (AtStaS, gi|332656706), Vigna angularis (VaStaS, gi|6634701), P. sativum (PsStaS, gil13992585), Cucumis melo (CmStaS, gil659101177) and Alonsoa meridionalis (AmStaS, gil21038869).

\section{HPAEC-PAD Enzyme Assay Design}

A StaS enzyme assay was established and optimized. Furthermore, a set of stabilizing co-factors $\left(1 \mathrm{mM} \mathrm{Mg}^{2+}\right.$, $1 \mathrm{mg} \mathrm{ml}^{-1}$ BSA, $0.1 \%$ Triton, $0.1 \%$ Tween 20 and $1 \mathrm{mM} \mathrm{DTT}$ ) was tested. To stabilize the StaS enzyme activity during the purification procedure we added $1 \mathrm{mM}$ DTT to the equilibration and elution buffer for the pre-packed Protino ${ }^{\circledR}$ Ni-TED 1000 columns. This was sufficient to stabilize StaS enzyme activity without further need of DTT in the StaS enzyme assay. The recombinant AtRS4 showed a detectable StaS enzyme activity on HPAEC-PAD system incubating $335 \mathrm{ng}$ of recombinant AtRS4 in $25 \mathrm{mM}$ K-phosphate (KOH, pH 7), $100 \mu \mathrm{M}$ Gol and $400 \mu \mathrm{M}$ Raf in $100 \mu \mathrm{l}$ enzyme assays for $1 \mathrm{~h}$ at $25^{\circ} \mathrm{C}$. Under these conditions recombinant AtRS4 catalyzes the conversion of Raf and Gol into Sta. A typical chromatogram with appropriate controls is shown in Figure 4. The Sta product formation is dependent on the presence of Gol and Raf and identical with the commercially available reference compound Sta. Concomitant, the intermediate Ino accumulates linearly with Sta product formation. These experiments confirm that the purified recombinant AtRS4 is indeed a StaS. Characterization of recombinant AtRS4 was performed in enzyme assays not exceeding $60 \mathrm{~min}$, in which the amount of Sta increased linear with reaction time (Supplementary Figure S5). At later time points the Sta product accumulation drops, indicating that either the optimum Raf to Sta product formation ratio is reached and a galactosyl unit distribution mechanism gets activated, or that product inhibition by Ino or Sta occurs.

\section{StaS Characterization}

StaS enzyme activity of recombinant AtRS4 was determined in different buffer systems at $\mathrm{pH} 7$ and at different $\mathrm{pH}$ values ranging from pH 6.0 to 8.0 (Figure 5A), using Sta product formation as the detection method. The maximum StaS enzyme activity was reached at $\mathrm{pH} 6$, whereas $65.8 \%$ of the StaS enzyme activity was measured at $\mathrm{pH} 8.0$, therefore we performed enzyme assays at a neutral $\mathrm{pH}$ of 7 with $89.5 \%$ StaS enzyme activity. Utilization of Na-phosphate and MES buffer ( $\mathrm{pH} \mathrm{7)}$, under standard conditions, showed $86.5 \pm 4.8 \%$, respectively, $82.5 \pm 1.8 \%$, of StaS enzyme activity compared with $100 \pm 7.2 \%$ StaS enzyme activity in K-phosphate buffer at the same $\mathrm{pH}$.

Recombinant AtRS4 showed StaS enzyme activity within a temperature range from 5 to $35^{\circ} \mathrm{C}$ (Figure 5B). The temperature optimum was located around $25^{\circ} \mathrm{C}$. At $5^{\circ} \mathrm{C}$ still $22.2 \%$ of StaS enzyme activity was sustained, whereas $98.3 \%$ of the StaS enzyme activity was lost at $40^{\circ} \mathrm{C}$ caused by protein inactivation. 
TABLE 1 | Identity and similarity calculation of stachyose synthase (StaS) and raffinose synthase (RafS) amino acid sequences.

\begin{tabular}{lllll}
\hline Whole sequence & VaStaS & PsStaS & CmStaS & AmStaS \\
\hline AtStaS (Identity) & $56 \%$ & $56 \%$ & $59 \%$ & $55 \%$ \\
AtStaS (Similarity) & $73 \%$ & $73 \%$ & $75 \%$ & $72 \%$ \\
Whole sequence & OsRafS & CsRafS & PsRafS & GmRafS \\
AtRafS (Identity) & $56 \%$ & $35 \%$ & $35 \%$ & $35 \%$ \\
AtRafS (Similarity) & $72 \%$ & $54 \%$ & $52 \%$ & $53 \%$ \\
Whole seqence & $\boldsymbol{A t R S 1}$ & $\boldsymbol{A t R S 2}$ & $\boldsymbol{A t R a f S}$ & AtRS6 \\
AtStaS (Identity) & $29 \%$ & $28 \%$ & $36 \%$ & $28 \%$ \\
AtStaS (Similarity) & $48 \%$ & $45 \%$ & $54 \%$ & $44 \%$ \\
N-terminus & $\boldsymbol{A t R a f S}$ & & & \\
AtStaS (Identity) & $28 \%$ & & & \\
AtStaS (Similarity) & $45 \%$ & & & \\
C-terminus & $\boldsymbol{A t R a f S}$ & & & \\
AtStaS (Identity) & $35 \%$ & & & \\
AtStaS (Similarity) & $58 \%$ & & &
\end{tabular}

Calculation was performed with GeneDoc (Nicholas et al., 1999). (AtRS1, gi|15222768), (AtRS2, gi|15230330), and (AtRS6, gi|334187792).

\section{Substrate Specificity and Product Formation}

We tested the putative RafS enzyme activity, offering recombinant AtRS4 different concentration ratios of Suc and $\mathrm{Gol}$ for $6 \mathrm{~h}$ incubation at $25^{\circ} \mathrm{C}$, which lead to a detectable RafS (Figure 6, reaction 1) as well as StaS (Figure 6, reaction 2) enzyme activity on HPAEC-PAD system. We could also observe the product formation of Ino and Gal in HPAECPAD enzyme assay controls offering recombinant AtRS4 only Gol, leading to the conclusion that recombinant AtRS4 possesses a galactosylhydrolase enzyme activity. Therefore, we tested the galactosylhydrolase enzyme activity offering recombinant AtRS4 either Sta (Figure 6, reaction 4) or Raf or Gol (Figure 6, reaction 3). Galactosylhydrolase enzyme activity could only be observed offering recombinant AtRS4 Sta or Gol. The presented results indicate that AtRS4 has a raffinose and high affinity stachyose synthase as well as a stachyose and Gol specific galactosylhydrolase enzyme activity.

Within $1 \mathrm{~h}$ recombinant AtRS4 catalyzed the conversion of Raf and Gol into Sta and Ino but failed to catalyze the conversion of Suc and Gol into Raf and Ino in HPAECPAD enzyme assays, indicating a very high substrate specificity of AtRS4 for Raf. Within $6 \mathrm{~h}$ recombinant AtRS4 catalyzed the conversion of Suc and Gol into Raf as well as Sta and Ino in HPAEC-PAD enzyme assays. Different Suc to Gol substrate concentration ratios showed impact on the Raf to Sta product formation ratio. Increasing Suc concentration with constant Gol concentration lead to an increased Raf (up to $500 \mathrm{pkat} \mathrm{mg}^{-1}$ protein) product formation (Figure $7 \mathrm{~A}$ ), whereas increasing Gol concentration with constant Suc concentration had no impact on Raf (approximately 100 pkat $\mathrm{mg}^{-1}$ protein) product formation (Figure 7B). Sta product formation showed in both assays similar product formation maxima, although Raf to Sta product formation ratios changed in favor of Sta offering recombinant AtRS4 higher Gol concentrations than $10 \mathrm{mM}$, due to the lack of increasing Raf product

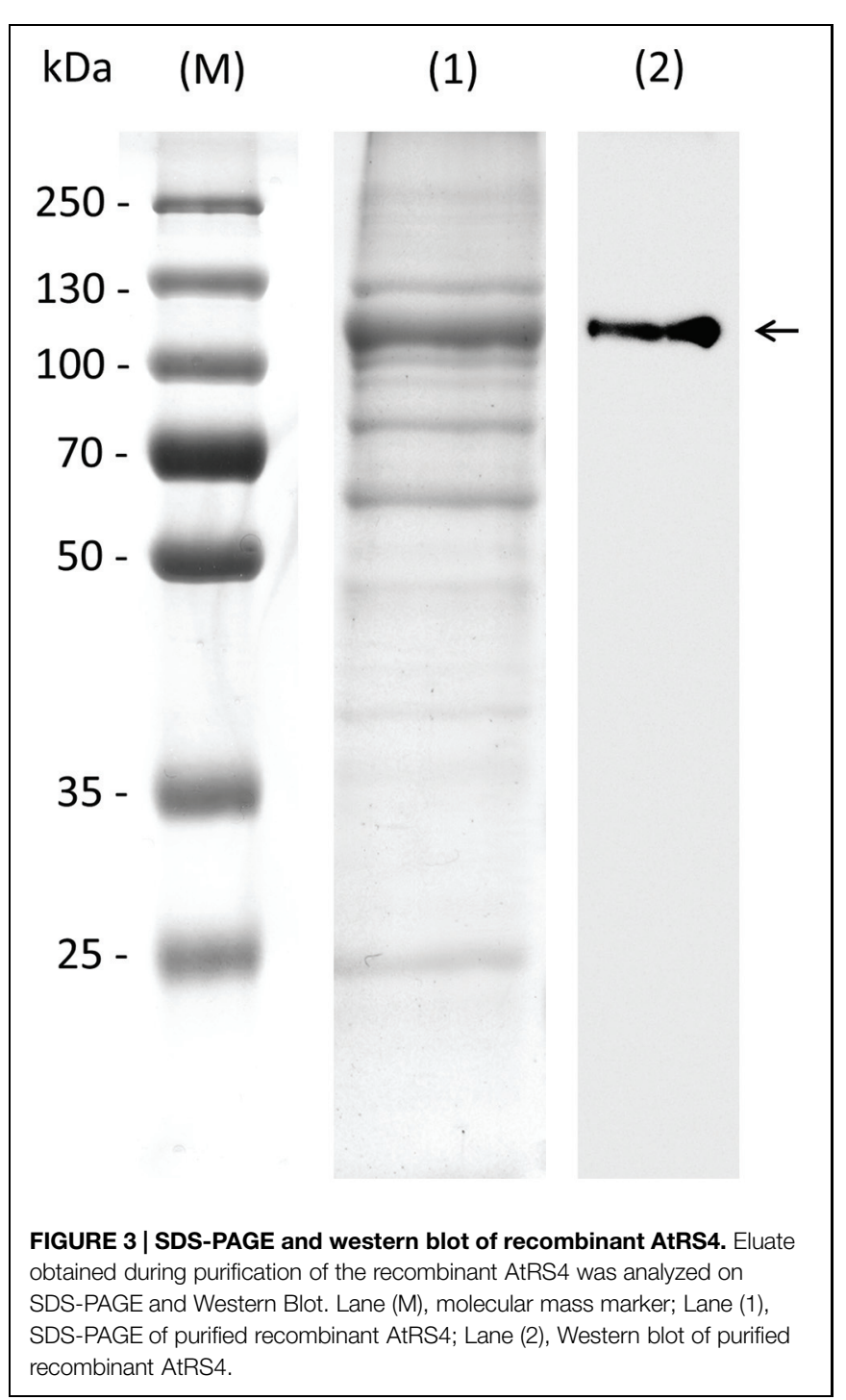

formation. Our presented results show, that AtRS4 is a sequential multifunctional RafS and StaS as well as a high affinity StaS, accepting only Raf and Gol for Sta product formation. Additionally, our results provide evidence, that AtRS4 possesses a Sta and Gol specific galactosylhydrolase enzyme activity.

\section{Kinetic Analysis}

Kinetic analysis of the StaS enzyme activity of recombinant AtRS4 was performed for the substrates Raf and Gol. The enzyme kinetic of recombinant AtRS4 for Raf (Figure 8A) showed a hyperbolic curve from which a $K_{\mathrm{m}}$ value for Raf of $259.2 \pm 21.15 \mu \mathrm{M}$ and a $V_{\max }$ value of $4,722 \pm 132.3$ pkat $\mathrm{mg}^{-1}$ protein was calculated using curve regression analysis with SigmaPlot 13.0 software. Substrate saturation curves of recombinant AtRS4 for Gol (Figure 8B) followed a hyperbolic curve according to Michaelis-Menten kinetic. The $K_{\mathrm{m}}$ value of recombinant AtRS4 for Gol in a substrate range from 50 to $1,200 \mu \mathrm{M}$ was calculated as 


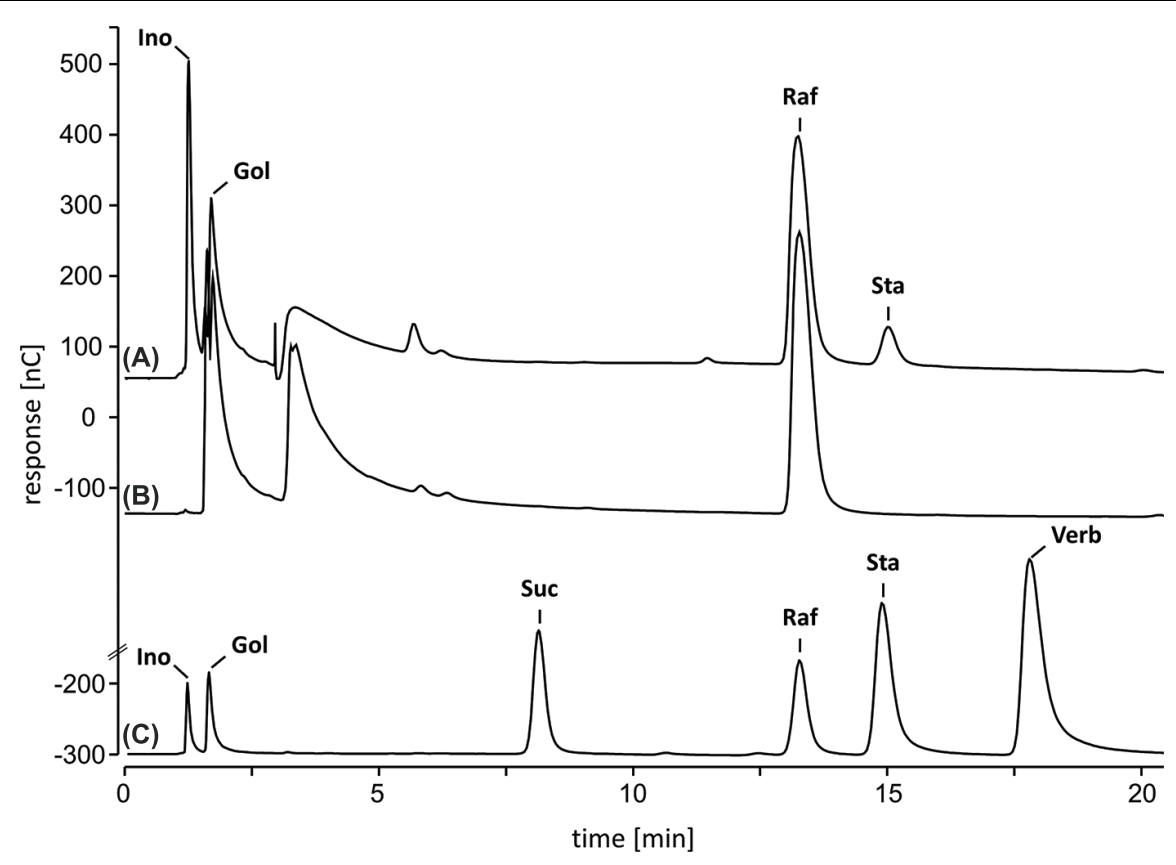

FIGURE 4 | High-performance anion-exchange chromatography with pulsed amperometric detection (HPAEC-PAD) enzyme assay. StaS enzyme activity of recombinant AtRS4 was tested. HPAEC-PAD chromatogram (A) indicates Sta product formation during enzyme reaction. HPAEC-PAD chromatogram (B) shows control without recombinant AtRS4. HPAEC-PAD chromatogram (C) shows $100 \mu \mathrm{M}$ Ino, Gol, Suc, Raf, Sta, and Verb as reference compounds.

$1,170 \pm 246.8 \mu \mathrm{M}$ and a $V_{\max }$ value of $8,911 \pm 1,105$ pkat $\mathrm{mg}^{-1}$ protein.

Kinetic analysis of the galactosylhydrolase enzyme activity of recombinant AtRS4 was performed for the substrates Sta and Gol. The enzyme kinetic of recombinant AtRS4 for Sta measuring Raf (Figure 8C) as well as the enzyme kinetic of recombinant AtRS4 for Sta measuring Gal (Figure 8D) showed an intermediate curve type between linear and hyperbolic curve. When using a global fit algorithm following Michaelis-Menten kinetic a $K_{\mathrm{m}}$ value for galactosylhydrolase activity for the substrate Sta was $1,059 \pm 269.3 \mu \mathrm{M}$ and a $V_{\max }$ value of $1,610 \pm 233.3{\text { pkat } \mathrm{mg}^{-1}}^{-1}$ protein for product Raf and a $K_{\mathrm{m}}$ value of $2,832 \pm 1043 \mu \mathrm{M}$ and a $V_{\max }$ value of $2,944 \pm 820.4$ pkat $\mathrm{mg}^{-1}$ protein for the product Gal. Substrate saturation curves of recombinant AtRS4 for Gol (Figure 8E) followed a hyperbolic curve according to Michaelis-Menten kinetic. The $K_{\mathrm{m}}$ value of recombinant AtRS4 for Gol in a substrate range from 50 to $1,200 \mu \mathrm{M}$ was calculated as $548.6 \pm 152 \mu \mathrm{M}$ and a $V_{\max }$ value of $1,653 \pm 205.3$ pkat $\mathrm{mg}^{-1}$ protein.

\section{Knockout Plants of AtRS4}

In order to analyze the function of AtRS4 for A. thaliana we isolated an insertional T-DNA mutant $\triangle A t R S 4$. To further characterize $\triangle A t R S 4$ mutant plants, we isolated RNA and reverse transcribed cDNA from siliques as well as from leaves of WT and mutant plants. While sqPCR from WT siliques showed a specific transcript AtRS4 PCR product, sqPCR from WT and $\triangle A t R S 4$ mutant leaves and from $\triangle A t R S 4$ mutant siliques cDNAs failed to amplify a PCR product (Figure 9). These results are confirmatory with expression data of At4g01970 obtained from the developmental map at the Arabidopsis eFP Browser (Winter et al., 2007).

\section{WSCs Extracts from $\Delta A t R S 4$ Mutant Seeds Show no Detectable Sta Concentration on HPAEC-PAD}

Water-soluble carbohydrates were extracted from seeds of WT and $\triangle A t R S 4$ mutant plants, and analyzed on HPAEC-PAD system (Figure 10A). The only RFOs present in WT seeds of A. thaliana were $\operatorname{Raf}\left(1,899.2 \pm 216.3 \mathrm{pmol} \mathrm{mg}^{-1} \mathrm{FW}\right)$ and Sta $\left(9,976.1 \pm 742.8 \mathrm{pmol} \mathrm{mg}^{-1} \mathrm{FW}\right)$. The only RFO present in $\triangle A t R S 4$ mutant plant seeds was Raf $(5,040.8 \pm 554.5 \mathrm{pmol}$ $\mathrm{mg}^{-1} \mathrm{FW}$ ) and a total loss of detectable Sta on HPAECPAD (Figure 10B). In $\triangle A t R S 4$ mutant plant seeds compared to WT plant seeds, Ino concentration was decreased by the 0.3 -fold, Gol concentration was increased by the 1.9-fold and Raf concentration was increased by the 2.6 -fold, occurring at concentrations of 5,040.8 $\pm 554.5 \mathrm{pmol} \mathrm{mg}^{-1} \mathrm{FW}$ (Figure 10B).

\section{Seed Germination Experiments}

To test whether $\triangle A t R S 4$ mutant seeds show any differences in the kinetic of imbibition and subsequent germination, we put WT and $\triangle A t R S 4$ seeds either on $0.5 \times$ MS agar plates or on $0.5 \%$ plant agar plates to let them germinate under standard growth conditions and observed the time period the seeds need to germinate. On $0.5 \times \mathrm{MS}$ agar plates, almost all $\triangle$ AtRS4 mutant seeds started to germinate after 2 days, while WT seeds did not seem to germinate as fast as $\triangle A t R S 4$ mutant seeds, whereas after 3 days, no difference could be 

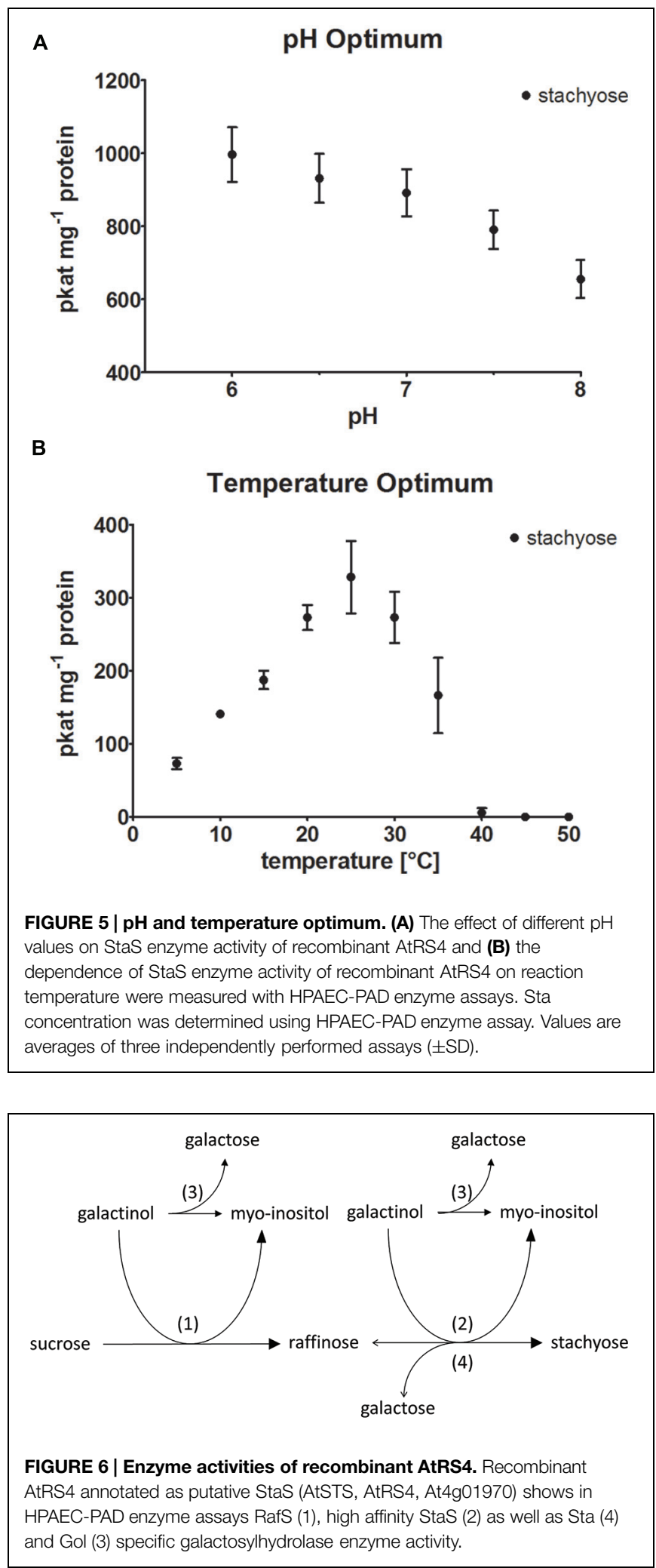

observed (Supplementary Figure S6). On $0.5 \times$ MS agar plates supplemented with $100 \mathrm{mM}$ and $150 \mathrm{mM} \mathrm{NaCl}$ kinetic of germination showed no differences, while after 20 days on
A

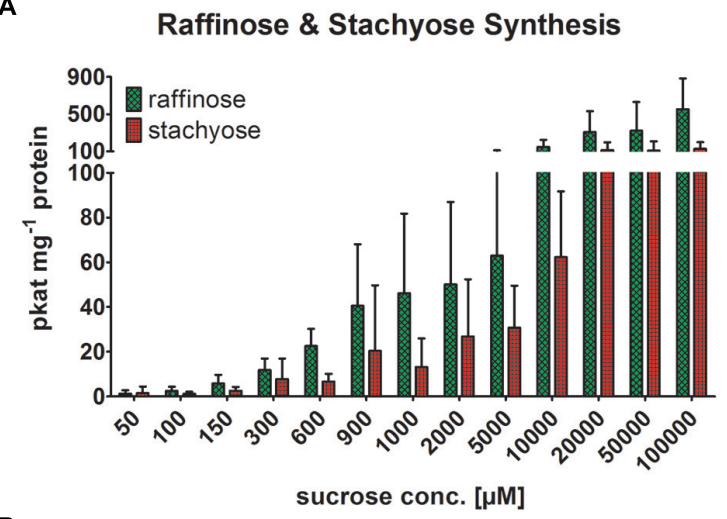

B

Raffinose \& Stachyose Synthesis

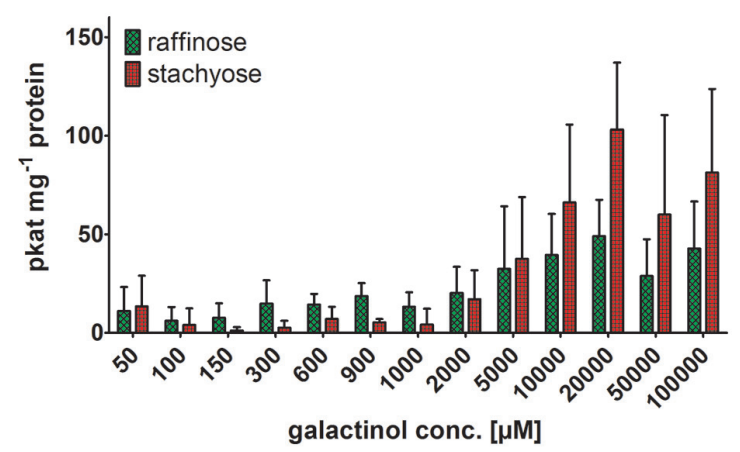

FIGURE 7 | Raf and Sta synthesis of recombinant AtRS4. The effect of different Suc to Gol substrate concentrations ratios on the Raf to Sta product formation ratio of recombinant AtRS4 was tested. (A) Suc in a substrate range from $50 \mu \mathrm{M}$ to $100 \mathrm{mM}$ was incubated for $6 \mathrm{~h}$ with $1 \mathrm{mM}$ Gol concentration and (B) Gol in a substrate range from $50 \mu \mathrm{M}$ to $100 \mathrm{mM}$ was incubated for $6 \mathrm{~h}$ with $1 \mathrm{mM}$ Suc and measured with HPAEC-PAD enzyme assays. Raf and Sta concentration was determined using HPAEC-PAD enzyme assay. Values are averages of three independently performed assays ( $\pm S D$ ).

plates supplemented with $200 \mathrm{mM} \mathrm{NaCl} 66 \%$ of WT seeds and in contrast $90 \%$ of $\triangle A t R S 4$ seeds germinated and died subsequently (Supplementary Figure S7). To avoid dormancy breaking signals like nitrate in plate media, we performed a seed germination experiment on $0.5 \%$ plant agar (Supplementary Figure S8) and observed germination of $75 \%$ of $\triangle A t R S 4$ seeds compared to $16 \%$ of WT seeds 2 days after sowing, while $82 \%$ of WT seeds germinated 3 days after sowing (Figure 11). To test whether segregating seeds from a heterozygous $\triangle A t R S 4$ mutant plant show a genotype-phenotype correlation on the kinetic of germination, we put those seeds on $0.5 \%$ plant agar plates and separated each day 5 just germinated seeds for genotyping. We did not find a correlation between the kinetic of germination and $\triangle A t R S 4$ genotype.

\section{Discussion}

In this study, we cloned AtRS4 cDNA encoding a putative StaS and RafS as well as galactosylhydrolase from A. thaliana. The 
A

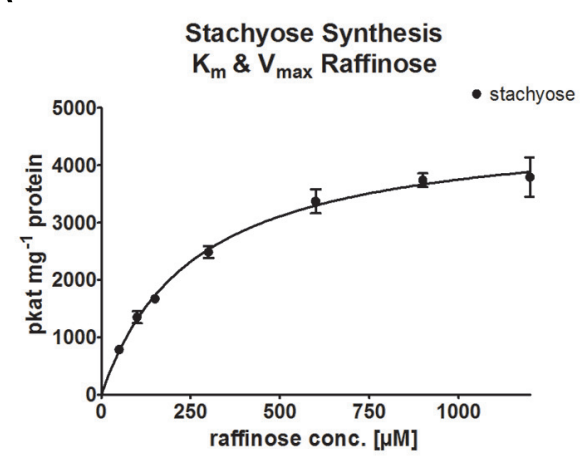

C

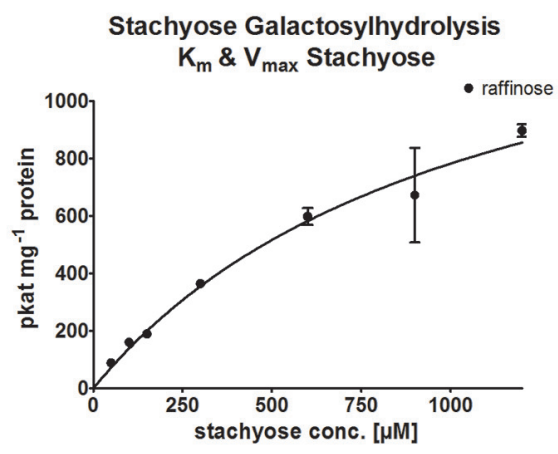

E

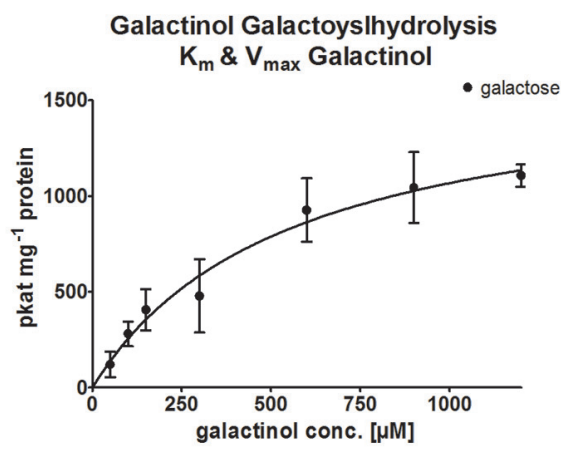

B

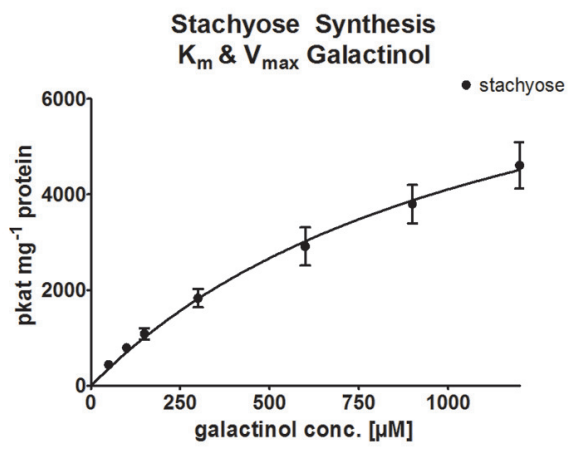

D

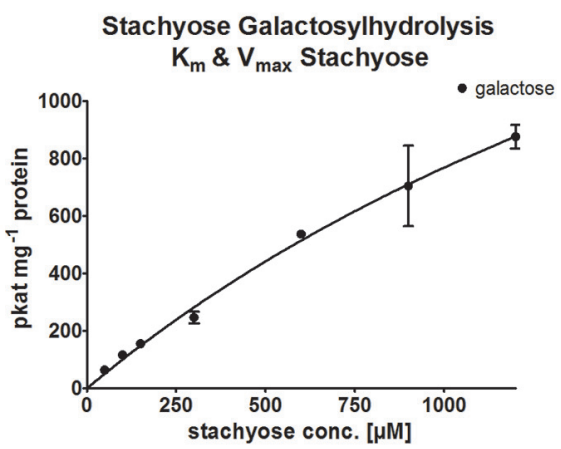

FIGURE 8 | Enzyme kinetics of recombinant AtRS4. Enzyme activity of recombinant AtRS4 was measured with varying concentrations of substrates (50 to $1,200 \mu \mathrm{M}$ ) under standard conditions for 60 min with HPAEC-PAD enzyme assays. Values are averages of three independently performed assays ( $\pm S D$ ).

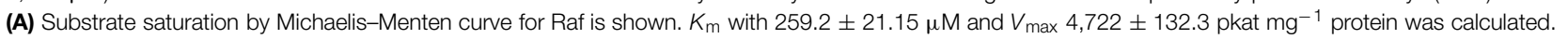

(B) Substrate saturation by Michaelis-Menten curve for Gol is shown. $K_{m}$ with 1,170 $\pm 246.8 \mu \mathrm{M}$ and $V_{\max }$ with $8,911 \pm 1,105 \mathrm{pkat}^{\mathrm{mg}}{ }^{-1}$ protein was calculated.

(C) Substrate saturation by Michaelis-Menten curve for Sta measuring Raf is shown. $K_{\mathrm{m}}$ with $1,059 \pm 269,3 \mu \mathrm{M}$ and $V_{\max } 1,610 \pm 233,3$ pkat mg ${ }^{-1}$ protein was calculated. (D) Substrate saturation by Michaelis-Menten curve for Sta measuring Gal is shown. $K_{\mathrm{m}}$ with 2,832 $\pm 1,043 \mu \mathrm{M}$ and $V_{\max } 2,944 \pm 820.4$ pkat $\mathrm{mg}^{-1}$ protein was calculated. (E) Substrate saturation by Michaelis-Menten curve for Gol measuring Gal is shown. $K_{m}$ with $548.6 \pm 152 \mu \mathrm{M}$ and $V_{\max }$ $1,653 \pm 205.3$ pkat $\mathrm{mg}^{-1}$ protein was calculated.

identity of the AtRS4 cDNA was verified by functional expression in E. coli cells. SDS-Blot, Western-Blot and different HPAECPAD enzyme assays demonstrated that the AtRS4 cDNA encodes a functional RafS and a high affinity StaS as well as a Raf and Gol specific galactosylhydrolase. The enzyme is multifunctional. The recombinant AtRS4 catalyzed the synthesis of Sta from Raf and Gol, and was able to utilize Suc and Gol as substrate to produce Raf as well as Sta. Beside the RafS and StaS enzyme activity, recombinant AtRS4 was able to hydrolyse Sta and Gol, but not Raf, providing evidence for a specific galactosylhydrolase enzyme activity of AtRS4. On 10\% SDS gels, the apparent molecular mass of the recombinant AtRS4 was about $100 \mathrm{kDa}$, which is in fairly good agreement with the molecular mass of $98 \mathrm{kDa}$ deduced from the amino acid sequence of the AtRS4 cDNA.

The amino acid sequence of AtRS4 (AtStaS) shares high homology (36\% identity and 54\% similarity, Table 1) with AtRS5 (AtRafS), an enzyme assumed to catalyze a very similar reaction. Both RafS and StaS utilize Gol as galactosyl donor and transfer them to acceptors that differ only in one galactosyl unit. However, despite these molecular and biochemical similarities, 


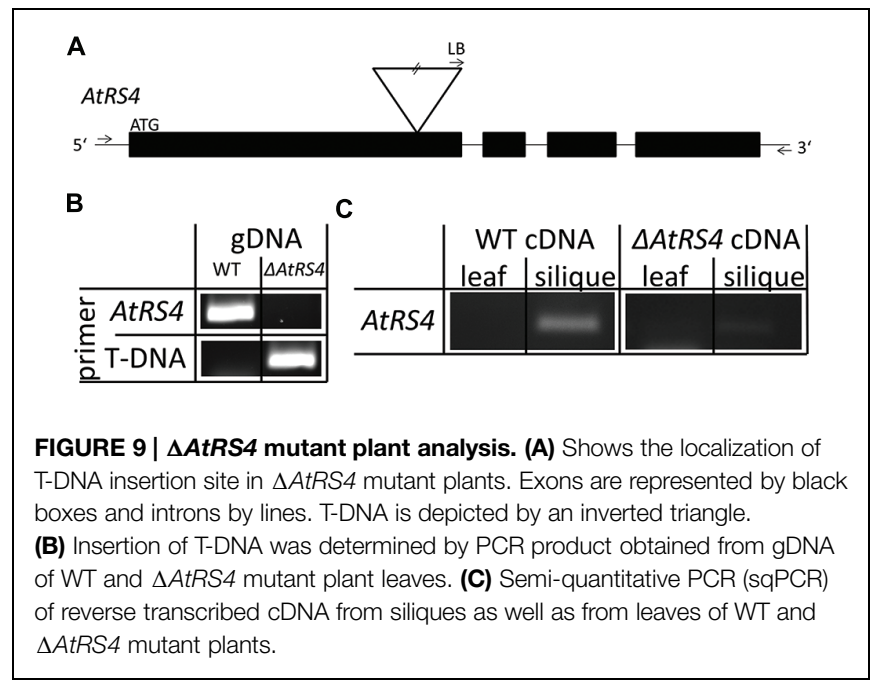

identified StaSs are totally inactive on Suc (Peterbauer and Richter, 1998; Hoch et al., 1999), while RafSs are inactive on Raf as acceptor (Lehle and Tanner, 1973). In this study, we could carve bioinformatically as well as biochemically out, that a single 80 amino acid long sequence block (Figure 2B) clearly divides the functional sequences of RafS and StaS in plant kingdom and serves as a reliable signature for RafSs and StaSs.

Biochemical data of plant RafSs are insufficiently reported, due to obvious expression problems in E. coli. Putative gene sequences have been reported for few plants, including $A$. thaliana. In the genome of A. thaliana, six putative RafS genes (AtRS1-6) are annotated. Little is known about these putative RafSs and their biochemical characteristics (Peters et al., 2010) and their contribution to the RFO physiology in A. thaliana (Egert et al., 2013). To our knowledge in this study we could for the first time purify a functional recombinant RafS from A. thaliana out of E. coli cells and characterize it biochemically. To elucidate

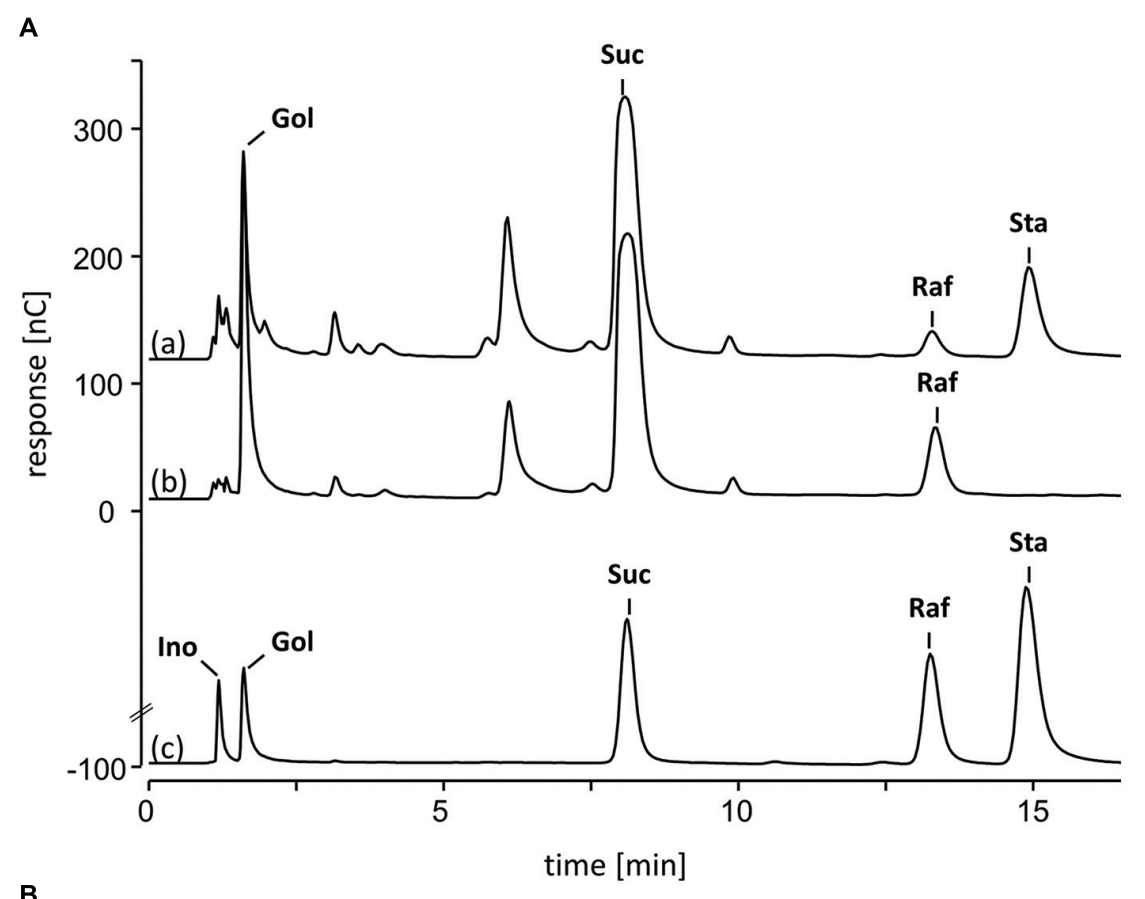

B
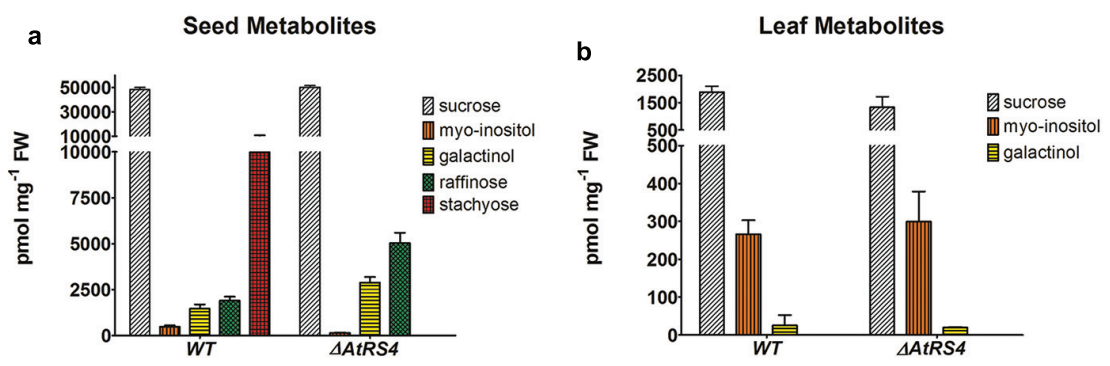

FIGURE 10 | Metabolite phenotype of $\triangle$ AtRS4 mutant seeds. (A) HPAEC-PAD chromatogram of water-soluble carbohydrates (WSCs) and sugar alcohols extracted from (a) WT seeds, (b) $\triangle A t R S 4$ mutant seeds and (c) $100 \mu \mathrm{M}$ Ino, Gol, Suc, Raf, and Sta as reference compounds. HPAEC-PAD chromatogram shows a total loss of Sta in $\triangle A t R S 4$ mutant seeds. (B) Metabolite Phenotype of (a) WT and $\triangle A t R S 4$ mutant seeds and of (b) WT and $\triangle$ AtRS4 mutant leaves. Values are averages of three independently performed measurements $( \pm S D)$. 


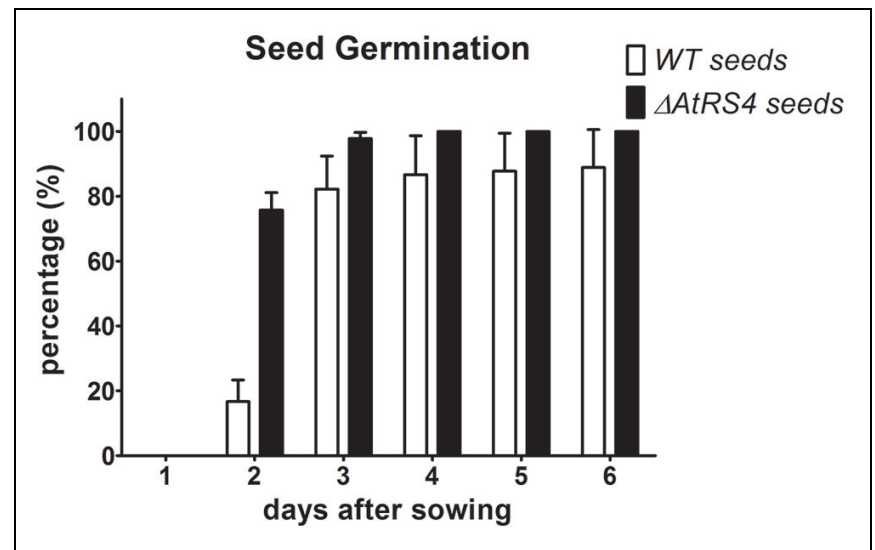

FIGURE 11 | Kinetic of WT and $\Delta$ AtRS4 seed germination. WT and $\triangle$ AtRS4 mutant seeds for germination experiment were sowed on $0.5 \%$ plant agar and grew under control growth conditions. Germination was defined as the time between sowing and protrusion of the radicle. Values are averages of three independently performed experiments $( \pm S D)$.

the biochemical functions and their contribution to the RFO physiology in A. thaliana the remaining putative RafS genes need to be cloned and functional expressed as recombinant protein.

Fructosyltransferases, which catalyze the synthesis of fructans from Suc, are related to invertases and are thought to have evolved from the latter by small mutational changes (Sprenger et al., 1995; Hellwege et al., 1997; Van Der Meer et al., 1998). In consideration of the high sequence homology of galactosyltransferases, including RafS and StaS, belonging to the glycoside hydrolase family $36^{\circ} \mathrm{C}$, a member of the $\alpha$-amylase family, this history of origins is also very likely for galactosyltransferases. Peterbauer et al. (1999) raised concerns over this theory, because no homologies between the amino acid sequence of StaS and those of $\alpha$-galactosidases were found and only acidic $\alpha$-galactosidases with a broad substrate specificity have been cloned (Overbeeke et al., 1989; Zhu and Goldstein, 1994; Davis et al., 1996, 1997). Distinct $\alpha$-galactosidases with high specificity toward RFOs and alkaline $\mathrm{pH}$ optima have been identified in leaves of Cucurbitaceae (Gaudreault and Webb, 1983; Gao and Schaffer, 1999), but the amino acid sequences of the latter $\alpha$-galactosidases had not been reported. Peters et al. (2010) could functionally identify AtRS2 (AtSIP2, At3g575209) as an alkaline $\alpha$-galactosidase with substrate specificity for Raf, but no RafS activity. Sequence research, clearly revealed also because of the high sequence homology between AtRS2 and AtRS4 (28\% identity and $45 \%$ similarity, Table 1), that galactosyltransferases and alkaline $\alpha$-galactosidases definitely belong to one glycoside hydrolase family, although their individual enzymatic function is not that clear and easy to predict based on bioinformatic homology searches. RafS and StaS are related to a family of unknown function called SIPs. Peterbauer et al. (2002) expressed curiosity to see whether these SIPs are glycosyltransferases or hydrolases. In this study, we could functionally identify AtRS4 as a RafS and a high affinity StaS, respectively, as a specific galactosyltransferase, as well as a Sta and Gol specific galactosylhydrolase, indicating that a separation between galactosyltransferase and galactosylhydrolases based on amino acid sequence is very difficult.

It is well reported that mature $A$. thaliana seeds accumulate substantial quantities of Sta and Raf (Ooms et al., 1993; Bentsink et al., 2000; Nishizawa-Yokoi et al., 2008). We hypothesized that if AtRS4 was the sole StaS in A. thaliana as suggested by the putative annotation in TAIR data base and no other of the five AtRS genes possesses StaS enzyme activity as described in the multifunctional StaS of Lentil seed (Hoch et al., 1999) and PsStaS (Peterbauer et al., 2002), then mature seeds from $\triangle A t R S 4$ mutant plants should be devoid of Sta accumulation, since no putative galactan:galactan galactosyltransferase (GGT) (Bachmann and Keller, 1995; Haab and Keller, 2002) is annotated in the genome of $A$. thaliana. Seeds of $\triangle A t R S 4$ mutant plants showed an absolute loss of detectable Sta on HPAEC-PAD. The concentration of Raf was increased by the 2.6-fold, whereas the concentrations of the other major seed WSCs, Ino, and Gol, were comparable between the mutants and those of WT plants (Figure 10). The absolute loss of Sta and the increased concentration of Raf by the 2.6-fold in $\triangle A t R S 4$ mutant seeds confirmed our hypothesis that AtRS4 is the sole StaS in A. thaliana.

Egert et al. (2013) hypothesized the existence of at least one other seed specific, as yet unidentified, RafS in A. thaliana, which is responsible for the partial Raf accumulation during seed development in $\triangle A t R S 5$ mutant plants. Our biochemical characterization of recombinant AtRS4 showed RafS and StaS enzyme activity, and was able to hydrolyse Sta into Raf, which represents the reverse reaction of the StaS enzyme activity. Recombinant AtRS4 was able to convert Suc and Gol into Raf and Sta, but was not able to hydrolyse Raf into Suc. Therefore we hypothesized that if AtRS4 would be the second seed specific A. thaliana RafS as suggested previously, then mature seeds from $\triangle A t R S 4$ mutant plants would have shown complete ablation of Sta accumulation and decreased concentrations of Raf by a 0.5 -fold. However, seeds of $\triangle A t R S 4$ mutant plants showed concentrations of Raf increased by 2.6 -fold, suggesting that the knockout of the multifunctional RFO synthase in the seeds of $\triangle A t R S 4$ mutant plants lead to a tailback of Raf and therefore the expected 0.5 -fold Raf decreased metabolic phenotype was covert. Our bioinformatical and biochemical results suggest AtRS4 as the second seed specific RafS as postulated by Egert et al. (2013), whereas absolute certainty could only be given by seed metabolite measurements of a crossed double knockout $\triangle A t R S 4 \& 5$ plant and biochemical characterisation of AtRS5.

The key regulation step of RFO biosynthesis is still controversial. Some reports favor GolS as the key enzyme whereas others consider substrate accumulation of initial substrates like Ino and Suc together with other feed-back loops as regulating step (Peterbauer et al., 2001; Karner et al., 2004; Lahuta et al., 2005; Bock et al., 2009). In this study we could clearly show that the concentration of Suc, respectively, the Suc to Gol substrate concentration ratio, has an impact on the Raf to Sta product formation ratio of recombinant AtRS4. High concentrations of Suc lead to higher concentrations of Raf, whereas the Sta concentration seems Suc and Gol concentration independent. These results lead to the conclusion, that Raf accumulation 
is controlled by the Suc concentration. Raf product formation takes recombinant AtRS4 much longer than Sta product formation. Once recombinant AtRS4 produced Raf, degradation to Suc is blocked due to the not detectable Raf specific galactosylhydrolase enzyme activity, whereas a multifunctional enzymatic distribution of the Raf and Sta ratio needed from the plant cell to adopt to the environment or, respectively, stress condition is possible. Egert et al. (2013) stated that the Sta accumulation in WT seeds $\left(1.24 \pm 0.076 \mathrm{mg} \mathrm{g}^{-1} \mathrm{DW}\right)$ and in seeds of two different $\triangle$ AtRS5 mutant lines $(1.11 \pm 0.11$ and $1.24 \pm 0.04 \mathrm{mg} \mathrm{g}^{-1} \mathrm{DW}$, respectively) show equal Sta concentrations, whereas Gol $(0.52 \pm 0.051$ and $0.54 \pm 0.026 \mathrm{mg}$ $\mathrm{g}^{-1} \mathrm{DW}$, respectively) increased almost threefold in seeds from the $\triangle A t R S 5$ mutant plants. In this paper, we could show that a total loss of Sta in $\triangle A t R S 4$ mutant seeds, leads to an increased Raf concentration by the 2.6-fold and Gol concentration by the 1.9-fold, favoring AtRS4 as the only StaS in A. thaliana, and as the key regulation step of Sta biosynthesis.

Sta is thought to be an important source of energy during seed germination. It has been hypothesized, that RFOs play a special role during early seed germination and that they are required for successful germination (Blöchl et al., 2007). Based on this knowledge, we hypothesized, that we could observe a germination phenotype of $\triangle A t R S 4$ mutant seeds, containing an increased Raf concentration by the 2.6-fold and a total loss of Sta. But contrary to our expectations of a delayed germination, we observed that, $\triangle A t R S 4$ mutant seeds germinated slightly earlier than WT seeds. Suggesting that a loss of Sta in A. thaliana seeds has no impact on germination time period or that the increased Raf concentration compensates or even speeds up germination. Clear evidence of the impact of Raf and Sta on germination kinetics could be derived from future germination experiments with WT, $\triangle A t R S 4, \triangle A t R S 5$, and especially $\triangle A t R S 4 \& 5$ mutant seeds, since seedlings from segregating heterozygous $\triangle A t R S 4$ plant showed no clear genotype-phenotype correlation.

Since AtRS5 is characterized as an abiotic stress-induced RafS, AtRS4 can be seen as a basic Raf and Sta supply multifunctional RFO synthase, which supplies the plant seed with constant Sta accumulation and its RafS activity, respectively accumulation, is controlled by the Suc concentration of the plant cell. Therefore we hypothesize, the better the plant is doing in the environment, the more Suc is produced and the more Raf is accumulated in seeds of the new generation, which provide more energy for germination and better adaption to the environmental conditions.

AtRS4 kinetics displayed much higher affinity toward Raf when assayed with $\mathrm{Gol}\left(K_{\mathrm{m}} 259.2 \mu \mathrm{M}\right)$, compared with estimated $K_{\mathrm{m}}$ values of $\mathrm{CmStaS}$ ( $K_{\mathrm{m}}$ between 3.7 and $15 \mathrm{mM}$; Huber et al., 1990; Holthaus and Schmitz, 1991), LcStaS ( $K_{\mathrm{m}} 9.7 \mathrm{mM}$; Hoch et al., 1999), PsStaS ( $K_{\mathrm{m}} 21.1 \mathrm{mM}$; Peterbauer et al., 2002), and

\section{References}

Aguilera, Y., Martín-Cabrejas, M. A., Benítez, V., Mollá, E., López-Andréu, F. J., and Esteban, R. M. (2009). Changes in carbohydrate fraction during dehydration process of common legumes. J. Food Composit. Anal. 22, 678-683. doi: 10.1016/j.jfca.2009.02.012
$\operatorname{VaStaS}\left(\mathrm{K}_{\mathrm{m}} 38.6 \mathrm{mM}\right.$; Peterbauer and Richter, 1998). Those high deviations within different $K_{\mathrm{m}}$ values are likely due to the fact, that all reported StaS kinetics were performed with seed purified enzyme or transformed cell lysate with unpurified recombinant StaS. The affinity toward Gol was also higher when assayed with Raf ( $\left.K_{\mathrm{m}} 1170 \mu \mathrm{M}\right)$, compared with estimated $K_{\mathrm{m}}$ values of LcStaS ( $K_{\mathrm{m}} 5.3 \mathrm{mM}$; Hoch et al., 1999) PsStaS ( $K_{\mathrm{m}}$ 13.9; Peterbauer et al., 2002), and VaStaS ( $K_{\mathrm{m}} 15.8 \mathrm{mM}$; Peterbauer and Richter, 1998). Our performed enzyme kinetics with recombinant purified AtRS4 confirmed very high substrate specificity and the advantage of using recombinant purified enzymes.

AtRS4 specific StaS activity [ $V_{\max }$ (Raf) 4,722 pkat $\mathrm{mg}^{-1}$ protein and $V_{\max }$ (Gol) 8,911 pkat $\mathrm{mg}^{-1}$ protein] was lower, but still comparable with specific StaS activity of LcStaS [ $V_{\max }$ (Raf) 9.09 nkat $\mathrm{mg}^{-1}$ protein and $V_{\max }$ (Gol) 21.6 nkat $\mathrm{mg}^{-1}$ protein] (Hoch et al., 1999), PsStaS ( $V_{\max } 33.7$ nkat $\mathrm{mg}^{-1}$ ) and VaStaS [ $V_{\max }$ (Raf) 11.7 nkat $\mathrm{mg}^{-1}$ protein (Peterbauer and Richter, 1998) and $V_{\max }$ (Raf) 0.8 nkat $\mathrm{mg}^{-1}$ protein (Peterbauer et al., 1999)]. Gol specific [ $V_{\max }$ (Gal) 1653 pkat $\mathrm{mg}^{-1}$ protein] galactosylhydrolase activity of AtRS4 was lower than specific StaS activity, favoring the synthesis rather than the galactosylhydrolase reaction. AtRS2 kinetics displayed comparable galactosylhydrolase activity $\left(V_{\max } 1.80\right.$ nkat $\left.\mathrm{mg}^{-1}\right)$ with AtRS4 kinetics, whereas substrate affinity of AtRS4 was much higher toward Gol $\left[\mathrm{K}_{\mathrm{m}}(\mathrm{Gal}) 548.6 \mu \mathrm{M}\right]$, compared with $K_{\mathrm{m}}$ value of AtRS2 $\left(K_{\mathrm{m}} 105 \mathrm{mM}\right)$.

In this paper, we report on the molecular cloning, functional expression in E. coli and biochemical characterisation of AtRS4 from $A$. thaliana with the help of a $\triangle A t R S 4$ mutant plant. The purified recombinant AtRS4 protein possesses a raffinose and high affinity stachyose synthase as well as stachyose and Gol specific galactosylhydrolase activity. A total loss of stachyose in $\triangle A t R S 4$ mutant seeds suggests that AtRS4 is responsible for stachyose accumulation in seeds of $A$. thaliana. AtRS4 represents a key regulation mechanism in the RFO physiology of $A$. thaliana due to its multifunctional enzyme activity.

\section{Acknowledgment}

This research was funded by the Austrian Science Fund (FWF): P27323-B22.

\section{Supplementary Material}

The Supplementary Material for this article can be found online at: http://journal.frontiersin.org/article/10.3389/fpls.2015.00789

Alonso, J. M., Stepanova, A. N., Leisse, T. J., Kim, C. J., Chen, H., Shinn, P., et al. (2003). Genome-wide insertional mutagenesis of Arabidopsis thaliana. Science 301, 653-657. doi: 10.1126/science.1086391

Arvidsson, S., Kwasniewski, M., Riaño-Pachón, D. M., and Mueller-Roeber, B. (2008). QuantPrime-a flexible tool for reliable high-throughput primer design for quantitative PCR. BMC Bioinform. 9:465. doi: 10.1186/1471-2105-9-465 
Bachmann, M., and Keller, F. (1995). Metabolism of the raffinose family oligosaccharides in leaves of Ajuga reptans L.(inter-and intracellular compartmentation). Plant Physiol. 109, 991-998.

Behmüller, R., Forstenlehner, I. C., Tenhaken, R., and Huber, C. G. (2014). Quantitative HPLC-MS analysis of nucleotide sugars in plant cells following off-line SPE sample preparation. Anal. Bioanal. Chem. 406, 3229-3237. doi: 10.1007/s00216-014-7746-3

Bentsink, L., Alonso-Blanco, C., Vreugdenhil, D., Tesnier, K., Groot, S. P., and Koornneef, M. (2000). Genetic analysis of seed-soluble oligosaccharides in relation to seed storability of Arabidopsis. Plant Physiol. 124, 1595-1604. doi: 10.1104/pp.124.4.1595

Bewley, J. D., and Black, M. (1994). Seeds. Berlin: Springer.

Blöchl, A., Peterbauer, T., and Richter, A. (2007). Inhibition of raffinose oligosaccharide breakdown delays germination of pea seeds J. Plant Physiol. 164, 1093-1096. doi: 10.1016/j.jplph.2006.10.010

Bock, C., Ray, H., and Georges, F. (2009). Down-regulation of galactinol synthesis in oilseed Brassica napus leads to significant reduction of antinutritional oligosaccharides This paper is one of a selection of papers published in a Special Issue from the National Research Council of Canada-Plant Biotechnology Institute. Botany 87, 597-603.

Chomczynski, P. (1993). A reagent for the single-step simultaneous isolation of RNA. DNA and proteins from cell and tissue samples. Biotechniques 15, 536-537.

Cristofaro, E., Mottu, F., and Wuhrmann, J. (1974). "Involvement of the raffinose family of oligosaccharides in flatulence," in Sugars in Nutrition, eds H. L. Sipple and K. W. McNutt (New York: Academic Press).

Davis, M. O., Hata, D. J., Johnson, S. A., Jones, D. E., Harmata, M. A., Evans, M. L., et al. (1997). Cloning, sequence, and expression of a blood group B active recombinant $\alpha$-D-galactosidase from pinto bean (Phaseolus vulgaris). IUBMB Life 42, 453-467. doi: 10.1080/15216549700202861

Davis, M. O., Hata, D. J., Johnson, S. A., Walker, J. C., and Smith, D. S. (1996). Cloning, expression and characterization of a blood group B active recombinant $\alpha$-d-galactosidase from soybean (Glycine max). IUBMB Life 39, 471-485. doi: $10.1080 / 15216549600201521$

Delzenne, N. M., and Roberfroid, M. (1994). Physiological effects of non-digestible oligosaccharides. LWT-Food Sci. Technol. 27, 1-6. doi: 10.1006/fstl.1994.1001

Devindra, S., Sreenivasa Rao, J., Krishnaswamy, P., and Bhaskar, V. (2011). Reduction of $\alpha$-galactoside content in red gram (Cajanus cajan L.) upon germination followed by heat treatment. J. Sci. Food Agric. 91, 1829-1835. doi: $10.1002 /$ jsfa.4391

Dierking, E. C., and Bilyeu, K. D. (2009). Raffinose and stachyose metabolism are not required for efficient soybean seed germination. J. Plant Physiol. 166, 1329-1335. doi: 10.1016/j.jplph.2009.01.008

Downie, B., and Bewley, J. D. (2000). Soluble sugar content of white spruce (Picea glauca) seeds during and after germination. Physiol. Plant. 110, 1-12. doi: 10.1034/j.1399-3054.2000.110101.x

Egert, A., Keller, F., and Peters, S. (2013). Abiotic stress-induced accumulation of raffinose in Arabidopsis leaves is mediated by a single raffinose synthase (RS5. At5g40390). BMC Plant Biol. 13:218. doi: 10.1186/1471-222 9-13-218

El-Adawy, T., Rahma, E., El-Bedawey, A., and El-Beltagy, A. (2003). Nutritional potential and functional properties of germinated mung bean, pea and lentil seeds Plant Foods Hum. Nutr. 58, 1-13. doi: 10.1023/A:10240631 05507

Elsayed, A. I., Rafudeen, M. S., and Golldack, D. (2013). Physiological aspects of raffinose family oligosaccharides in plants: protection against abiotic stress. Plant Biol. doi: 10.1111/plb.12053

Feng, S., Saw, C. L., Lee, Y. K., and Huang, D. (2008). Novel process of fermenting black soybean [Glycine max (L.) Merrill] yogurt with dramatically reduced flatulence-causing oligosaccharides but enriched soy phytoalexins. J. Agric. Food Chem. 56, 10078-10084. doi: 10.1021/jf801905y

Frias, J., Bakhsh, A., Jones, D., Arthur, A., Vidal-Valverde, C., Rhodes, M., et al. (1999). Genetic analysis of the raffinose oligosaccharide pathway in lentil seeds J. Exp. Bot. 50, 469-476. doi: 10.1093/jxb/50.333.469

Gangl, R., Behmüller, R., and Tenhaken, R. (2014). Molecular cloning of a novel glucuronokinase/putative pyrophosphorylase from Zebrafish acting in an UDP-glucuronic acid salvage pathway. PLOS ONE 9:e89690. doi: 10.1371/journal.pone.0089690
Gao, Z., and Schaffer, A. A. (1999). A novel alkaline $\alpha$-galactosidase from melon fruit with a substrate preference for raffinose. Plant Physiol. 119, 979-988. doi: 10.1104/pp.119.3.979

Gaudreault, P.-R., and Webb, J. A. (1983). Partial purification and properties of an alkaline $\alpha$-galactosidase from mature leaves of Cucurbita pepo. Plant Physiol. 71, 662-668. doi: 10.1104/pp.71.3.662

Haab, C. I., and Keller, F. (2002). Purification and characterization of the raffinose oligosaccharide chain elongation enzyme, galactan: galactan galactosyltransferase (GGT), from Ajuga reptans leaves. Physiol. Plant. 114, 361-371. doi: 10.1034/j.1399-3054.2002.1140305.x

Han, I. H., and Baik, B.-K. (2006). Oligosaccharide content and composition of legumes and their reduction by soaking, cooking, ultrasound, and high hydrostatic pressure. Cereal Chem. 83, 428-433. doi: 10.1094/CC-83-0428

Hellwege, E. M., Gritscher, D., Willmitzer, L., and Heyer, A. G. (1997). Transgenic potato tubers accumulate high levels of 1-kestose and nystose: functional identification of a sucrose sucrose 1-fructosyltransferase of artichoke (Cynara scolymus) blossom discs. Plant J. 12, 1057-1065. doi: 10.1046/j.1365313X.1997.12051057.X

Hoch, G., Peterbauer, T., and Richter, A. (1999). Purification and characterization of stachyose synthase from lentil (Lens culinaris) seeds: galactopinitol and stachyose synthesis. Arch. Biochem. Biophys. 366, 75-81. doi: 10.1006/abbi.1999.1212

Holthaus, U., and Schmitz, K. (1991). Stachyose synthesis in mature leaves of Cucumis melo. Purification and characterization of stachyose synthase (EC 2.4. 1.67). Planta 184, 525-531. doi: 10.1007/BF00197902

Huber, J. L., Pharr, D. M., and Huber, S. C. (1990). Partial purification and characterization of stachyose synthase in leaves of Cucumis sativus and Cucumis melo: utilization of a rapid assay for myo-inositol. Plant Sci. 69, 179-188. doi: 10.1016/0168-9452(90)90116-6

Iftime, D., Hannah, M. A., Peterbauer, T., and Heyer, A. G. (2011). Stachyose in the cytosol does not influence freezing tolerance of transgenic Arabidopsis expressing stachyose synthase from adzuki bean. Plant Sci. 180, 24-30. doi: 10.1016/j.plantsci.2010.07.012

Karner, U., Peterbauer, T., Raboy, V., Jones, D. A., Hedley, C. L., and Richter, A. (2004). myo-Inositol and sucrose concentrations affect the accumulation of raffinose family oligosaccharides in seeds J. Exp. Bot. 55, 1981-1987. doi: 10.1093/jxb/erh216

Khalil, A. H., and Mansour, E. H. (1998). Alginate encapsulated bifidobacteria survival in mayonnaise. J. Food Sci. 63, 702-705. doi: 10.1111/j.13652621.1998.tb15817.x

Kulkarni, D. S., Kapanoor, S. S., Girigouda, K., Kote, N. V., and Mulimani, V. H. (2006). Reduction of flatus-inducing factors in soymilk by immobilized alphagalactosidase. Biotechnol. Appl. Biochem. 45, 51-57. doi: 10.1042/BA20060027

Kumar, V., Rani, A., Goyal, L., Dixit, A. K., Manjaya, J., Dev, J., et al. (2010). Sucrose and raffinose family oligosaccharides (RFOs) in soybean seeds as influenced by genotype and growing location. J. Agric. Food Chem. 58, 5081-5085. doi: $10.1021 /$ jf903141s

Kuo, T. M., Vanmiddlesworth, J. F., and Wolf, W. J. (1988). Content of raffinose oligosaccharides and sucrose in various plant seeds J. Agric. Food Chem. 36, 32-36. doi: 10.1021/jf00079a008

Lahuta, L. B., Górecki, R. J., Gojło, E., and Horbowicz, M. (2005). Differences in accumulation of soluble $\alpha$-galactosides during seed maturation of several Vicia species. Acta Physiol. Plant. 27, 163-171. doi: 10.1007/s11738-005-0020-8

Lahuta, L. B., Goszczyńska, J., Horbowicz, M., Hołdyński, C., and Górecki, R. J. (2010). Cyclitols affect accumulation of $\alpha$-d-galactosides in developing Vicia seeds Acta physiol. Plant. 32, 933-942. doi: 10.1007/s11738-010-0481-2

Lehle, L., and Tanner, W. (1973). The function of myo-inositol in the biosynthesis of raffinose. Eur. J. Biochem. 38, 103-110. doi: 10.1111/j.14321033.1973.tb03039.x

Lehle, L., Tanner, W., and Kandler, O. (1970). Myo-inositol, a cofactor in the biosynthesis of raffinose. Hoppe Seylers Z Physiol. Chem. 351, 1494-1498. doi: 10.1515/bchm2.1970.351.2.1494

Liu, J.-J. J., Krenz, D. C., Galvez, A. F., and De Lumen, B. O. (1998). Galactinol synthase (GS): increased enzyme activity and levels of mRNA due to cold and desiccation. Plant Sci. 134, 11-20. doi: 10.1016/S0168-9452(98)00042-9

Liu, J. J., Odegard, W., and De Lumen, B. (1995). Galactinol synthase from kidney bean cotyledon and zucchini leaf (purification and $\mathrm{N}$-terminal sequences). Plant Physiol. 109, 505-511. doi: 10.1104/pp.109.2.505 
Liu, X., Champagne, C. P., Lee, B. H., Boye, J. I., and Casgrain, M. (2014). Thermostability of probiotics and their $\alpha$-galactosidases and the potential for bean products. Biotechnol. Res. Int. 2014:472723. doi: 10.1155/2014/472723

Lunn, J. E., Feil, R., Hendriks, J. H., Gibon, Y., Morcuende, R., Osuna, D., et al. (2006). Sugar-induced increases in trehalose 6-phosphate are correlated with redox activation of ADPglucose pyrophosphorylase and higher rates of starch synthesis in Arabidopsis thaliana. Biochem. J. 397, 139-148. doi: 10.1042/BJ20060083

Martín-Cabrejas, M. A., Díaz, M. F., Aguilera, Y., Benítez, V., Mollá, E., and Esteban, R. M. (2008). Influence of germination on the soluble carbohydrates and dietary fibre fractions in non-conventional legumes. Food Chem. 107, 1045-1052. doi: 10.1016/j.foodchem.2007.09.020

Nicholas, K., Nicholas, H., and Deerfield, D. (1999). II (1997) GeneDoc: analysis and visualization of genetic variation. Embnew. news 4, 14.

Nishizawa, A., Yabuta, Y., and Shigeoka, S. (2008). Galactinol and raffinose constitute a novel function to protect plants from oxidative damage. Plant Physiol. 147, 1251-1263. doi: 10.1104/pp.108.122465

Nishizawa-Yokoi, A., Yabuta, Y., and Shigeoka, S. (2008). The contribution of carbohydrates including raffinose family oligosaccharides and sugar alcohols to protection of plant cells from oxidative damage. Plant Signal. Behav. 3, 1016-1018. doi: $10.4161 /$ psb.6738

Obendorf, R. L. (1997). Oligosaccharides and galactosyl cyclitols in seed desiccation tolerance. Seed Sci. Res. 7, 63-74. doi: 10.1016/j.jplph.2015.06.013

Ooms, J., Leon-Kloosterziel, K. M., Bartels, D., Koornneef, M., and Karssen, C. M. (1993). Acquisition of desiccation tolerance and longevity in seeds of Arabidopsis thaliana (A Comparative Study Using Abscisic Acid-Insensitive abi3 Mutants). Plant Physiol. 102, 1185-1191.

Osumi, C., Nozaki, J., and Kida, T. (2005). DNA encoding raffinose synthase from soybean. Google Patents.

Osumi, C., Nozaki, J., and Kida, T. (2008). Soybean raffinose synthase and a method for producing raffinose. Google Patents.

Overbeeke, N., Fellinger, A. J., Toonen, M. Y., Van Wassenaar, D., and Verrips, C. T. (1989). Cloning and nucleotide sequence of the $\alpha$-galactosidase cDNA from Cyamopsis tetragonoloba (guar). Plant Mol. Biol. 13, 541-550. doi: 10.1007/BF00027314

Patil, A. G. G., Kote, N. V., and Mulimani, V. (2009). Enzymatic removal of flatulence-inducing sugars in chickpea milk using free and polyvinyl alcohol immobilized $\alpha$-galactosidase from Aspergillus oryzae. J. Indust. Microbiol. Biotechnol. 36, 29-33. doi: 10.1007/s10295-008-0467-x

Peterbauer, T., Lahuta, L. B., Blöchl, A., Mucha, J., Jones, D. A., Hedley, C. L., et al. (2001). Analysis of the raffinose family oligosaccharide pathway in pea seeds with contrasting carbohydrate composition. Plant Physiol. 127, 1764-1772. doi: 10.1104/pp.010534

Peterbauer, T., Mucha, J., Mach, L., and Richter, A. (2002). Chain Elongation of raffinose in pea seeds Isolation, characterization, and molecular cloning of mutifunctional enzyme catalyzing the synthesis of stachyose and verbascose. J. Biol. Chem. 277, 194-200.

Peterbauer, T., Mucha, J., Mayer, U., Popp, M., Glossl, J., and Richter, A. (1999). Stachyose synthesis in seeds of adzuki bean (Vigna angularis): molecular cloning and functional expression of stachyose synthase. Plant J. 20, 509-518. doi: 10.1046/j.1365-313X.1999.00618.x

Peterbauer, T., and Richter, A. (1998). Galactosylononitol and stachyose synthesis in seeds of adzuki bean purification and characterization of stachyose synthase. Plant Physiol. 117, 165-172. doi: 10.1104/pp.117.1.165

Peters, S., Egert, A., Stieger, B., and Keller, F. (2010). Functional identification of Arabidopsis ATSIP2 (At3g57520) as an alkaline alpha-galactosidase with a substrate specificity for raffinose and an apparent sink-specific expression pattern. Plant Cell Physiol. 51, 1815-1819. doi: 10.1093/pcp/pcq127

Pharr, D., Sox, H., Locy, R., and Huber, S. (1981). Partial characterization of the galactinol forming enzyme from leaves of cucumis sativus L. Plant Sci. Lett. 23, 25-33. doi: 10.1016/0304-4211(81)90021-3
Qiu, D., Vuong, T., Valliyodan, B., Shi, H., Guo, B., Shannon, J. G., et al. (2015). Identification and characterization of a stachyose synthase gene controlling reduced stachyose content in soybean. Theor. Appl. Genet. doi: 10.1007/S00122015-2575-0 [Epub ahead of print].

Roberfroid, M. (2002). Functional food concept and its application to prebiotics. Dig. Liver Dis. 34, S105-S110. doi: 10.1016/S1590-8658(02)80176-1

Schneider, C. A., Rasband, W. S., and Eliceiri, K. W. (2012). NIH Image to ImageJ: 25 years of image analysis. Nat. Methods 9, 671-675. doi: 10.1038/nmeth.2089

Sievers, F., Wilm, A., Dineen, D., Gibson, T. J., Karplus, K., Li, W., et al. (2011). Fast, scalable generation of high-quality protein multiple sequence alignments using Clustal Omega. Mol. Syst. Biol. 7, 539. doi: 10.1038/msb.2011.75

Slominski, B., Campbell, L., and Guenter, W. (1994). Oligosaccharides in canola meal and their effect on nonstarch polysaccharide digestibility and true metabolizable energy in poultry. Poult. Sci. 73, 156-162. doi: $10.3382 /$ ps.0730156

Sosulski, F., Elkowicz, L., and Reichert, R. (1982). Oligosaccharides in eleven legumes and their air-classified protein and starch fractions. J. Food Sci. 47, 498-502. doi: 10.1111/j.1365-2621.1982.tb10111.x

Sprenger, N., Bortlik, K., Brandt, A., Boller, T., and Wiemken, A. (1995). Purification, cloning, and functional expression of sucrose: fructan 6-fructosyltransferase, a key enzyme of fructan synthesis in barley. Proc. Natl. Acad. Sci. U.S.A. 92, 11652-11656. doi: 10.1073/pnas.92.2 5.11652

Swennen, K., Courtin, C. M., and Delcour, J. A. (2006). Non-digestible oligosaccharides with prebiotic properties. Crit. Rev. Food Sci. Nutr. 46, 459471. doi: 10.1080/10408390500215746

Taji, T., Ohsumi, C., Iuchi, S., Seki, M., Kasuga, M., Kobayashi, M., et al. (2002). Important roles of drought- and cold-inducible genes for galactinol synthase in stress tolerance in Arabidopsis thaliana. Plant J. 29, 417-426. doi: 10.1046/j.0960-7412.2001.01227.x

Tanner, W., and Kandler, O. (1968). Myo-inositol, a cofactor in the biosynthesis of stachyose. Eur. J. Biochem. 4, 233-239. doi: 10.1111/j.1432-1033.1968.tb00199.x

Van Der Meer, I. M., Koops, A. J., Hakkert, J. C., and Van Tunen, A. J. (1998). Cloning of the fructan biosynthesis pathway of Jerusalem artichoke. Plant J. 15, 489-500. doi: 10.1046/j.1365-313X.1998.00230.x

Vidal-Valverde, C., Frias, J., Sierra, I., Blazquez, I., Lambein, F., and Kuo, Y.-H. (2002). New functional legume foods by germination: effect on the nutritive value of beans, lentils and peas. Eur. Food Res. Technol. 215, 472-477. doi: 10.1007/s00217-002-0602-2

Winter, D., Vinegar, B., Nahal, H., Ammar, R., Wilson, G. V., and Provart, N. J. (2007). An "Electronic Fluorescent Pictograph" browser for exploring and analyzing large-scale biological data sets. PLoS ONE 2:e718. doi: 10.1371/journal.pone.0000718

Zhao, T.-Y., Corum Iii, J. W., Mullen, J., Meeley, R. B., Helentjaris, T., Martin, D., et al. (2006). An alkaline $\alpha$-galactosidase transcript is present in maize seeds and cultured embryo cells, and accumulates during stress. Seed Sci. Res. 16, 107-121. doi: 10.1079/SSR2006243

Zhu, A., and Goldstein, J. (1994). Cloning and functional expression of a cDNA encoding coffee bean $\alpha$-galactosidase. Gene 140, 227-231. doi: 10.1016/03781119(94)90548-7

Conflict of Interest Statement: The authors declare that the research was conducted in the absence of any commercial or financial relationships that could be construed as a potential conflict of interest.

Copyright (c) 2015 Gangl, Behmüller and Tenhaken. This is an open-access article distributed under the terms of the Creative Commons Attribution License (CC BY). The use, distribution or reproduction in other forums is permitted, provided the original author(s) or licensor are credited and that the original publication in this journal is cited, in accordance with accepted academic practice. No use, distribution or reproduction is permitted which does not comply with these terms. 